NBER WORKING PAPER SERIES

\title{
WHAT WERE THE ODDS? ESTIMATING THE MARKET'S PROBABILITY OF UNCERTAIN EVENTS
}

\author{
Ashley Langer \\ Derek Lemoine \\ Working Paper 28265 \\ http://www.nber.org/papers/w28265 \\ NATIONAL BUREAU OF ECONOMIC RESEARCH \\ 1050 Massachusetts Avenue \\ Cambridge, MA 02138 \\ December 2020
}

We are grateful to David Brown, David Card, Gautam Gowrisankaran, Hidehiko Ichimura, Diego Kaenzig, David Schreindorfer, and Tiemen Woutersen for feedback, to Justin Wolfers for conference discussion, to the University of Arizona's Eller Center for Management Innovations in Healthcare and Institute of the Environment for financial support, and to Wendan Zhang and Frances Slater for research assistance. We also thank seminar participants at Arizona State University, ASSA 2020, HEC Montreal, TREE, University of Arizona, University of California Berkeley, and Yale. We gratefully acknowledge an allocation of computer time from the University of Arizona's High Performance Computing (HPC) facility. The views expressed herein are those of the authors and do not necessarily reflect the views of the National Bureau of Economic Research.

NBER working papers are circulated for discussion and comment purposes. They have not been peer-reviewed or been subject to the review by the NBER Board of Directors that accompanies official NBER publications.

(C) 2020 by Ashley Langer and Derek Lemoine. All rights reserved. Short sections of text, not to exceed two paragraphs, may be quoted without explicit permission provided that full credit, including $(\odot$ notice, is given to the source. 
What Were the Odds? Estimating the Market's Probability of Uncertain Events Ashley Langer and Derek Lemoine

NBER Working Paper No. 28265

December 2020

JEL No. C58,G13,L71,Q43

\begin{abstract}
$\underline{\text { ABSTRACT }}$
An event study generates only a lower bound on the full effect of an event unless researchers know the probability that investors assigned to the event before it occurred. We develop two model-free methods for recovering the market's priced-in probability of events. These methods require running event studies in financial options to complement the standard event study in stock prices. Validating both approaches, we estimate that the 2016 U.S. election outcome had a $12 \%$ chance of occurring. This probability is consistent with contemporary polling, bookmaker, and prediction market estimates. Demonstrating the usefulness of our approaches, we show that many OPEC meetings' outcomes were well-anticipated. OPEC retained substantial influence on world oil prices even as the U.S. increased oil production.
\end{abstract}

\author{
Ashley Langer \\ Department of Economics \\ University of Arizona \\ McClelland Hall 401 \\ Tucson, AZ 85721 \\ and NBER \\ alanger@email.arizona.edu \\ Derek Lemoine \\ Department of Economics \\ University of Arizona \\ McClelland Hall 401EE \\ Tucson, AZ 85721 \\ and NBER \\ dlemoine@email.arizona.edu
}

A data appendix is available at http://www.nber.org/data-appendix/w28265 


\section{Introduction}

Event studies are standard techniques for estimating financial markets' response to news releases. However, it is widely recognized that event studies capture the full market valuation of news only when that news is a complete surprise. ${ }^{1}$ Such cases are rare: few things that happen were previously judged to have zero probability. When stock prices partially anticipate events, event studies measure the effect of becoming sure about the news rather than of learning news that is completely new. The event study methodology then provides only a lower bound on the consequences of news - and that bound can be arbitrarily loose.

In this paper we develop two new model-free techniques for estimating the market probability of realized events from widely traded financial options. We validate these techniques on the 2016 U.S. election and then apply them to a series of announcements by the Organization of the Petroleum Exporting Countries (OPEC) oil market cartel. Our new methods enable researchers to recover the full effect of events, which is important for applications ranging from minimum wage studies (e.g., Card and Krueger, 1995; Bell and Machin, 2017) to taxation (e.g., Auerbach and Hassett, 2007) to health policy (e.g., Al-Ississ and Miller, 2013) to environmental policy (e.g., Bushnell et al., 2013). Our new methods are also important because the probabilities of the events can themselves be of direct interest. For instance, we can estimate firms' differential exposure to uncertainty, which could be critical to understanding the role of uncertainty in the economy.

The intuition underlying our first approach is straightforward. Imagine that a financial option has value only if a given event occurs: there is some chance of exercising the option conditional on the event occurring but very little chance of exercising it otherwise. In an oil market application, this might be an option that gives the holder the right to purchase oil at a high "strike" price after an OPEC decision on whether to cut production. If OPEC cuts production, then it is likely that the market price of oil will end up above the strike price, making the option valuable. But if OPEC does not cut production, then the market price of oil is highly unlikely to be greater than the strike price, making the option nearly worthless. On the day before the event, the value of this option is approximately the probability of the event occurring times the value of the option if the event occurs. On the

\footnotetext{
${ }^{1}$ Card and Krueger (1995)[314] explain that "one difficulty in interpreting" their finding that minimum wages have only small effects on stock prices is "the fact that investors might have anticipated the news before it was released". MacKinlay $(1997,37)$ laments that while event studies are in principle a promising tool for recovering "the wealth effects of regulatory changes for affected entities", their usefulness has been limited by the fact that "regulatory changes are often debated in the political arena over time", with their effects incorporated into stock prices only gradually.
} 
day after the event occurs, the value of this option is simply the value of the option given that the event has occurred. If nothing else changed over the event window, the ratio of the option's price before the event to its price after the event is the priced-in probability of the event occurring. By running an event study in option prices, researchers can estimate what the change in an option's price would have been if nothing but the event had occurred. This approach requires that some liquidly traded options would have had little value if the event had turned out differently but retained value after the realized event. In practice, this approach requires an event to be sufficiently important for the price of an option's underlying asset and requires that sufficiently deep out-of-the-money options (i.e., options with extreme strike prices) are liquidly traded. ${ }^{2}$

Our second method of estimating an event's probability relies on different identifying assumptions and does not rely on deep out-of-the-money options. If the market knows that an event will occur on a given date and if a stock's volatility in the days and weeks immediately after the event does not depend directly on the event's outcome, then the event-induced change in the stock's expected near-term variance can be used to recover the probability of the event. For instance, traders typically know the day that OPEC will meet and might expect that the supply and demand shocks that will induce price volatility in the few weeks immediately after the meeting are independent of the meeting's outcome. Under minimal assumptions, the price of a portfolio of options reveals the market's expectation of the variance in a stock's price (Martin, 2017). We recover the market's probability of events by estimating the event-induced change in the price of this portfolio. Intuitively, differencing the preand post-event expected variances eliminates the post-event variance but retains the variance induced by uncertainty about the event's realization. This latter variance is merely a transformation of the probability we seek.

We validate our methods by estimating the probability of the Republican sweep of the 2016 U.S. election. Prediction markets, bookmakers, and polling-driven models imply probabilities ranging from 0.07 to 0.26 . We recover a probability of 0.12 . Our two methods generate nearly identical results, despite relying on different identifying assumptions. And the empirical results support the theoretical predictions: we demonstrate that the out-of-the-money option approach requires using only extreme strikes and restricting attention to firms with especially large event-day stock price

\footnotetext{
${ }^{2}$ In general, options with extreme strike prices would not be worthless if the event fails to occur because there may still be some chance of reaching an extreme stock price. We show that the estimated probability is then an upper bound on the market's priced-in probability of the event occurring. We describe theoretically motivated restrictions designed to generate a tight bound and find that this bound does appear to be tight in our application to the 2016 U.S. election.
} 
movements, and we demonstrate that the variance swap approach requires removing firms that were not exposed to the election outcome. Recent work has been interested in the implications of event studies of this election (e.g., Mukanjari and Sterner, 2018; Wagner et al., 2018a,b; Ramelli et al., 2019). Our results imply that the full effect of the election is $15 \%$ larger than implied by standard event study estimates.

We show that estimating these probabilities can be critical for understanding economic forces. In particular, we estimate probabilities for 13 OPEC meetings from 2011 to 2016. Conventional event studies show that OPEC meetings largely failed to move oil prices between 2012 and 2016, which coincided with a period of sustained oil production quotas by OPEC member countries. However, previous work has speculated that similar null results may merely reflect that anticipation of OPEC announcements masks the true influence of OPEC (e.g., Draper, 1984; Deaves and Krinsky, 1992; Wirl and Kujundzic, 2004; Spencer and Bredin, 2019). Indeed, we find that most meetings did not produce news that was fairly surprising. The few events that produced surprising news did have large effects on oil markets. In particular, markets anticipated OPEC's failure to reach agreement on new production quotas in December 2015 and June 2016. Standard event studies suggest that these meetings did not strongly affect oil markets, but we find that these were in fact two of the more important meetings after adjusting for market anticipation.

\section{The usefulness of priced-in event probabilities}

Recovering event probabilities is widely acknowledged to be important for measuring the full magnitude of events and for understanding whether events are unimportant or just anticipated (e.g., Card and Krueger, 1995; Karpoff et al., 1996; Hallock, 1998). Measuring the full magnitude of events is critical for testing theoretical predictions (e.g., Hennessy and Strebulaev, 2020), conducting cost-benefit analysis (e.g., Meng, 2017), and estimating damages in court settings (e.g., Cornell and Morgan, 1990).

Many other lines of economic inquiry would also benefit from credibly estimated probabilities. First, substantial recent research has attempted to measure the level and impact of policy uncertainty (e.g., Baker et al., 2014; Dorsey, 2019; Bianconi et al., 2020). Our methods recover new measures of this uncertainty. Further, our methods can identify how exposure to uncertainty varies over firms, as when firms are exposed to different aspects of an election, court ruling, or legislation. Recent work has used linguistic analysis to connect firm-level uncertainty to decisions on hiring, investment, and lobbying decisions (Hassan et al., 2019; Handley and Li, 2020). Our methods are a valuable complement to this textual work both in relying on preferences revealed through transactions and in measuring exposure to uncertainty 
about more narrowly defined events.

Second, some research seeks to aggregate or compare different events over time in a way that is similar to our OPEC analysis (e.g., Bronars and Deere, 1990; Farber and Hallock, 2009; Kogan et al., 2017). Without knowing the underlying probability of each event, it is impossible to distinguish between events that have different effects (whether over time or across firms) and events that are better-anticipated under some conditions than others. Researchers have long noted that cross-sectional analyses could be severely biased - even to the point of estimating the wrong sign - when the market's ability to forecast events varies with firm characteristics (e.g., Lanen and Thompson, 1988; MacKinlay, 1997; Bhagat and Romano, 2002). Our methods enable future studies to control for the priced-in probability of the event.

Third, researchers have used close elections as randomized experiments (e.g., Lee, 2008), but Caughey and Sekhon (2011) show that the outcomes of close elections may not be random. Our methods allow researchers to identify the elections that market participants viewed as effectively random, ${ }^{3}$ allowing researchers to use only those elections that were truly unexpected as randomized experiments.

Finally, researchers are interested in the risk premia placed on different states of the world, determined by variation in the stochastic discount factor. Our methods allow for new means of identifying how the stochastic discount factor varies with event outcomes. We recover risk-neutral probabilities, which reweight "objective" or "physical" probabilities by marginal utility and are the probabilities needed to correct event study estimates. ${ }^{4}$ If researchers use other approaches to pin down physical probabilities, then these events' risk-neutral probabilities inform us about investors' expectations of consumption in the realized state versus in other possible states. $^{5}$

\section{Previous approaches to correcting event studies for partial anticipation}

Researchers have long recognized the need to measure or control for the likelihood of an event (e.g., Ball, 1972; Binder, 1985; Malatesta and Thompson, 1985; MacKinlay,

\footnotetext{
${ }^{3}$ This identification requires that the elections be too "small" to bear much of a risk premium (so that the estimated risk-neutral probabilities roughly correspond to physical probabilities) but be important enough to affect some firms' stock prices.

${ }^{4}$ Risk-neutral probabilities differ from objective probabilities when there is a risk premium. The existence or magnitude of risk premia is immaterial to the present paper.

${ }^{5}$ For instance, if some elections are decided by a coin flip (e.g. Virginia's 94th District in 2017, which maintained the Republican majority in the House of Delegates) or are shown to be effectively random through the types of balance tests described by Caughey and Sekhon (2011), then the risk-neutral probability of these elections tells us which candidate or party was anticipated to have more favorable consequences for aggregate consumption.
} 
1997; Lamdin, 2001). Previous literature has adopted several approaches. The simplest solution is to select events that the researcher judges to be relatively surprising. But this assumption can be difficult to test and limits the applicability of the event study approach. ${ }^{6}$ A related stream of research attempts to reduce the effects of partial anticipation by extending the event window to include earlier time periods in the hope that the extended event window will capture any information leakage (e.g., Jayachandran, 2006; Auerbach and Hassett, 2007; Linn, 2010; Lee and Mas, 2012; Al-Ississ and Miller, 2013). In some cases, the event window becomes years-long. However, extending the event window decreases the plausibility of the event study methodology's identifying assumption that no information is revealed in the event window other than the event itself and also reduces the power to detect true effects (Brown and Warner, 1985; Kothari and Warner, 1997). For these and other reasons, many recommend keeping the event window as short as possible (e.g., Bhagat and Romano, 2002; Kothari and Warner, 2007).

Instead of trying to minimize the market probability of an event, two strands of research seek to recover that probability directly. First, many researchers use prediction market contracts to measure event probabilities (e.g., Roberts, 1990; Herron, 2000; Hughes, 2006; Knight, 2006; Snowberg et al., 2007; Lange and Linn, 2008; Wolfers and Zitzewitz, 2009; Imai and Shelton, 2011; Snowberg et al., 2011; Lemoine, 2017; Meng, 2017). Prediction markets can be a valuable source of information when the proper contracts exist, but this method faces significant hurdles in many applications. In particular, prediction market contracts are not available for many events of interest or may be written on only part of an event (e.g., the outcome of a presidential election but not of each down-ballot race). Further, prediction market contracts can be quite thinly traded, rapidly fluctuating prices can be hard to map to end-of-day stock market data, and prediction market participants might not hold the same beliefs as financial market participants. Prediction markets are powerful sources of information, but it is important to have other means of estimating event probabilities.

We show that bets made in ordinary options markets can encode the same information as specialized prediction markets. Options markets are attractive because they can be quite thickly traded, are closely linked to stock markets of interest in event studies, and may be more informationally efficient than stock markets (Black,

${ }^{6}$ Dube et al. (2011) find that even top-secret coup authorizations leak to the markets. Auerbach and Hassett (2007) combine estimates from several legislative events in the hope that the cumulative effect of incrementally increasing the probability of successful legislation approximates the effect of truly surprising legislation. Of course, some researchers do claim that their events were complete surprises (e.g., Bell and Machin, 2017). Our methods allow them to test such claims. 
1975; Easley et al., 1998; Pan and Poteshman, 2006; Johnson and So, 2012). A few papers in the finance literature have previously inferred the priced-in probability of events from the prices of financial options (Gemmill, 1992; Barraclough et al., 2013; Borochin and Golec, 2016; Carvalho and Guimaraes, 2018). These papers assume that options are priced according to specific parametric models and search for the event probability that reconciles observed option prices and theoretical option prices. However, as recognized by these authors, the distributional assumptions about stock prices that underpin these parametric models are commonly violated in practice. ${ }^{7}$ For instance, discrepancies between actual option prices and theoretical option prices generate well-known "anomalies" such as implied volatility smirks and smiles. When a theoretical model does not correctly predict option prices, including a probabilistic event adds at least one additional parameter that can improve the fit to observed option prices even if there were in fact no chance of an event.

Our new methods retain the advantages of using options markets but do not impose parametric assumptions. ${ }^{8}$ They are therefore not vulnerable to conventional option pricing "anomalies". Our methods for estimating the event probability require only the absence of arbitrage and either (i) that some out-of-the-money options have nontrivial value following the realized event outcome but not following other possible outcomes or (ii) that expected volatility in the days after an event does not depend on the event's realization. The latter is among the assumptions imposed in Gemmill (1992) and Carvalho and Guimaraes (2018), so our second method can be viewed as generalizing prior methods to eliminate parametric assumptions. ${ }^{9}$

\footnotetext{
${ }^{7}$ In fact, each of these papers uses a different option pricing model. Their various assumptions conflict with each other.

${ }^{8}$ Some other finance literature is more loosely related to the present paper. Gürkaynak et al. (2020) show how heteroskedastic responses to events identify non-headline news. Kelly et al. (2016) use financial options to estimate how much news is likely to be released by upcoming events. Whereas they seek the spread of possible outcomes, we seek the probability of the realized outcome, and whereas they need the date at which news will be released to be known well in advance (they study national elections and global summits), we propose a method that allows the date to be unknown in advance. Acharya (1993) studies the probability of endogenous events such as corporate announcements. We focus on policy events that affect a cross-section of firms and are not endogenous to any one firm. van Tassel (2016) and Fisman and Zitzewitz (2019) use stock and option prices, respectively, to recover investors' post-event beliefs. We recover investors' pre-event beliefs. Finally, Martin (2017), among others, shows how to use variation in option prices across strikes to recover the probability of sufficiently large losses. We show how to use variation over time to recover the probability of realized events.

${ }^{9}$ In concurrent work, Grinblatt and Wan (2020) argue that one can in principle back out riskneutral probabilities from the prices of options traded before an event. Their approach requires the full state space to be specified. In contrast, we use time series variation in option prices to recover the risk-neutral probability of the realized event without needing to explicitly specify the possible
} 


\section{Outline}

The next section describes the setting and defines the bias present in standard event studies. Section 3 derives the two new approaches to recovering an event's probability from options data. Section 4 explains how we take these theoretical approaches to the data, and Section 5 recovers probabilities for the 2016 U.S. election and for OPEC meetings. Section 6 concludes. The appendix contains supporting empirical analysis, theoretical extensions, and formal derivations.

\section{Setting}

We begin by developing a generic reduced-form representation of stock prices around an event. Consider a case with only a single firm. Its stock price reflects information about an upcoming event and all information about the state of the world beyond the event (such as earnings forecasts and interest rates). Formally, the price of the firm's stock is $S\left(\omega_{t}, e\right)$, where $\omega_{t} \in \mathcal{R}^{N}$ captures all payoff-relevant non-event news and $e \in\{L, H\}$ captures all event-related news. ${ }^{10}$ We write $S_{t}$ for the observed stock price, $S_{t}^{L}$ for $S\left(\omega_{t}, L\right)$, and $S_{t}^{H}$ for $S\left(\omega_{t}, H\right)$.

We study the beliefs of a representative market investor. Investors know $\omega_{t}$ at all times $t$, but they do not know whether $e=L$ or $e=H$ until time $\tau{ }^{11}$ At all times after $\tau$, observed stock prices $S_{t}$ are either $S_{t}^{H}$ or $S_{t}^{L}$. Let the time $t$ representative agent assign risk-neutral probability $p_{t}^{H}$ to $e=H$ and risk-neutral probability $p_{t}^{L}=1-p_{t}^{H}$ to state $e=L .^{12}$ Assume that event uncertainty affects payoffs only through the realized event $e$ (i.e., $p_{t}^{H}$ is independent of $\omega_{t}$ ), as when changes in event uncertainty do not lead firms to take actions that directly change their exposure to other shocks.

states or the form of the event's effect.

${ }^{10} \mathrm{We}$ write the discrete component as binary, but this choice is not restrictive. If, for instance, outcome $H$ is realized and extreme, then we can aggregate all of the other possible outcomes into a single indicator $L$ and treat $S\left(\omega_{t}, L\right)$ as an expected value over these outcomes. For the derivation when the event is not extreme, see Appendix C.2

${ }^{11}$ Until Section 3.2, we do not specify whether investors know the value of $\tau$ in advance.

${ }^{12}$ Absence of arbitrage ensures the existence of a risk-neutral measure, and the risk-neutral measure is unique if markets are complete. The risk-neutral measure can be interpreted as embedding risk into the probability weights by adjusting "physical" probabilities for the representative agent's risk aversion. For more on risk-neutral pricing, see standard asset pricing texts such as Björk (2004) or Cochrane (2005). 


\subsection{The Bias in the Standard Event Study Methodology}

Before we discuss how to recover event probabilities, we now review how partially anticipated events challenge the standard event study methodology. Without loss of generality, assume that event $H$ occurs. An event study aims to recover the full effect of the event, $S_{\tau-1}^{H}-S_{\tau-1}^{L}$, where $S_{\tau-1}^{H}$ and $S_{\tau-1}^{L}$ indicate what the time $\tau-1$ stock price would have been if the upcoming event's outcome were known to be $H$ or $L$, respectively. In order to estimate this difference, researchers regress stock returns $\left(S_{\tau} / S_{\tau-1}\right)$ on controls and an indicator for the first day $(\tau)$ on which the event outcome is known. The identifying assumption is that the controls account for anything other than the event that occurs between time $\tau-1$ and time $\tau$ (i.e., for the difference between $\omega_{\tau}$ and $\omega_{\tau-1}$ ). If there are multiple firms, then the identifying assumption becomes that, once the researcher includes controls, the expected value across firms of all residual non-event stock price news between $\tau-1$ and $\tau$ is zero. ${ }^{13}$

If the identifying assumption is satisfied, then the standard approach recovers $S_{\tau-1}^{H}-S_{\tau-1}$, the ceteris paribus change in the stock price at the time of the event. In the absence of arbitrage, the observed time $\tau-1$ stock price must be the probabilityweighted average of the stock price if event $L$ occurs and the stock price if event $H$ occurs:

$$
S_{\tau-1}=p_{\tau-1}^{L} S_{\tau-1}^{L}+p_{\tau-1}^{H} S_{\tau-1}^{H} .
$$

Rearranging and adding $S_{\tau-1}^{H}$ to both sides yields:

$$
S_{\tau-1}^{H}-S_{\tau-1}=\left(1-p_{\tau-1}^{H}\right)\left[S_{\tau-1}^{H}-S_{\tau-1}^{L}\right] .
$$

As is well known (e.g., Snowberg et al., 2011), the estimated event effect $\left(S_{\tau-1}^{H}-S_{\tau-1}\right)$ is less than the full event effect $\left(S_{\tau-1}^{H}-S_{\tau-1}^{L}\right)$ because some of the event outcome is already "priced in" before the event occurs. Researchers recover the true value of the event from the change in stock prices only when the event outcome is completely unexpected at $\tau-1$ (i.e., only as $p_{\tau-1}^{H} \rightarrow 0$ ). For this reason, researchers have sought events that are surprises. Unfortunately, an event study measures only an arbitrarily small fraction of the true event effect as the probability of the realized event outcome becomes large (i.e., as $p_{\tau-1}^{H} \rightarrow 1$ ). Event studies provide only a lower bound - and potentially only a very loose lower bound - for the implications of an event in the absence of information about $p_{\tau-1}^{H}$.

\footnotetext{
${ }^{13}$ See Campbell et al. (1997, Chapter 4), MacKinlay (1997), and Kothari and Warner (2007), among others, for reviews of event study methods.
} 


\section{Two Model-Free Approaches to Recovering the Event Probability from Options Data}

We propose two new approaches to recovering $p_{\tau-1}^{H}$ from time series variation in options prices. The first approach identifies this probability from changes in tail probabilities, and the second approach identifies the probability from changes in a stock's expected variance. We formally derive each approach in this section before detailing how we empirically implement each approach in Section 4.

\subsection{Using the Change in Tail Probabilities}

A call (put) option on a stock confers the right-but not the obligation - to buy (sell) the stock at a defined "strike" price $K$ on a defined expiration date $T .{ }^{14}$ A call option's value derives from the chance that the underlying stock's price will be higher than the strike price at the expiration date, in which case the option holder can buy the stock at the strike price, sell it at the market price, and keep the difference. If, on the other hand, the stock price at the expiration date is less than the strike price, the option holder should allow the option to expire unexecuted. Thus, the date $x$ value of the call option, $C_{x, T}\left(S_{x}, K\right)$, is the expected difference between the stock price and the strike conditional on that difference being positive:

$C_{x, T}\left(S_{x}, K\right)=\frac{1}{R_{x, T}} \int_{K}^{\infty}\left(S_{T}-K\right)\left[\left[1-p_{x}^{H}\right] f_{x}\left(S_{T} \mid S_{x}^{L}, L\right)+p_{x}^{H} f_{x}\left(S_{T} \mid S_{x}^{H}, H\right)\right] \mathrm{d} S_{T}$,

where we explicitly condition the risk-neutral distribution $f_{x}(\cdot)$ of $S_{T}$ on the time $x$ stock price $S_{x}$ and event outcome $e$ and where $R_{x, T} \geq 1$ is the gross risk-free rate from time $x$ to $T$. A put option is priced analogously, recognizing that its value derives from the chance that the underlying stock's price will be less than the strike price at the expiration date.

Now consider the effect of an event that occurred at time $\tau$. From the previous expression, the time $\tau-1$ price of a call option is

$$
C_{\tau-1, T}\left(S_{\tau-1}, K\right)=p_{\tau-1}^{H} C_{\tau-1, T}^{H}\left(S_{\tau-1}^{H}, K\right)+\left(1-p_{\tau-1}^{H}\right) C_{\tau-1, T}^{L}\left(S_{\tau-1}^{L}, K\right)
$$

\footnotetext{
${ }^{14}$ We model options as "European", even though most traded options are "American" options that allow the holder to exercise the option before $T$. This distinction is unlikely to be quantitatively important. Appendix C.1 extends the analysis to American options, showing that the results converge to the case of a European option as the time to maturity shrinks. In the empirical application, we focus on options with the shortest time to maturity, drop firms with high dividend yields that might make early exercise attractive, and, for other reasons given below, emphasize call options. These restrictions combine to limit the early exercise premium and thus to limit any difference between the prices of American and European options.
} 
where $C_{\tau-1, T}^{e}\left(S_{\tau-1}^{e}, K\right)$ is the value of the option at time $\tau-1$ if it was already known that the event's outcome would be $e$. Assume, without loss of generality, that outcome $H$ was realized at time $\tau$. We can then estimate $C_{\tau-1, T}^{H}\left(S_{\tau-1}^{H}, K\right)$ under standard event study assumptions. Dividing both sides of equation (4) by $C_{\tau-1, T}^{H}\left(S_{\tau-1}^{H}, K\right)$, we have:

$$
\frac{C_{\tau-1, T}\left(S_{\tau-1}, K\right)}{C_{\tau-1, T}^{H}\left(S_{\tau-1}^{H}, K\right)}=p_{\tau-1}^{H}+\left(1-p_{\tau-1}^{H}\right) \frac{C_{\tau-1, T}^{L}\left(S_{\tau-1}^{L}, K\right)}{C_{\tau-1, T}^{H}\left(S_{\tau-1}^{H}, K\right)} \triangleq \bar{p} .
$$

The ratio of the observed and counterfactual pre-event option prices is equal to the risk-neutral probability of the event outcome plus a "bias" term that depends on $C_{\tau-1, T}^{L}\left(S_{\tau-1}^{L}, K\right)$, the unobserved value of the option if the counterfactual event outcome had occurred. We label the ratio $\bar{p}$. Standard arbitrage bounds (e.g., Cochrane, 2005) require $C_{\tau-1, T}^{L}\left(S_{\tau-1}^{L}, K\right) \geq 0$ and $C_{\tau-1, T}^{H}\left(S_{\tau-1}^{H}, K\right) \geq 0$. Therefore $\bar{p}$ is at least as large as the true event probability $p_{\tau-1}^{H}$ and approaches this probability as the value of the option under the counterfactual event outcome approaches 0 .

The bias term must be small if $\bar{p}$ is to be useful for recovering $p_{\tau-1}^{H}$. Assume that the event increases stock prices in sufficiently extreme states of the world: there exists some $\bar{S}$ such that $S\left(\omega_{t}, H\right)>\bar{S}$ implies $S\left(\omega_{t}, H\right)>S\left(\omega_{t}, L\right){ }^{15}$ Given that infinite prices are not possible, the conditional distributions $f_{x}\left(S_{T} \mid S_{x}^{L}, L\right)$ and $f_{x}\left(S_{T} \mid S_{x}^{H}, H\right)$ converge to zero as $S_{T}$ grows. $C_{\tau-1, T}^{L}\left(S_{\tau-1}^{L}, K\right)$, the value of the call option conditional on outcome $L$, must converge to zero in the strike price $K$ more quickly than does $C_{\tau-1, T}^{H}\left(S_{\tau-1}^{H}, K\right)$. Equation (5) then shows that $\bar{p}$ converges to $p_{\tau-1}^{H}$ for some $K$ that is sufficiently large but not so large as to drive $C_{\tau-1, T}^{H}\left(S_{\tau-1}^{H}, K\right)$ to zero. Finally, conditional on a given event probability and a given strike, the difference $C_{\tau-1, T}^{H}\left(S_{\tau-1}^{H}, K\right)-C_{\tau-1, T}^{L}\left(S_{\tau-1}^{L}, K\right)$ is likely to be larger when the event has a larger effect on the underlying stock price. This means that the bias in equation (5) is likely to be small for a broader range of strikes when the event increases the stock price by a large amount.

Figure 1 depicts the intuition. Imagine that event $H$ leads to high stock prices and event $L$ leads to low stock prices. Conditional on the information available just before the event occurs (at time $\tau-1$ ), the risk-neutral distribution of prices for the stock at the expiration date $T$ is the dashed line $f_{\tau-1}\left(S_{T} \mid S_{\tau-1}\right)$, which is a mixture of the distribution conditional on event $H$ occurring (the long-dashed

\footnotetext{
${ }^{15}$ This assumption does not require that the event can have only two possible outcomes. Instead, this assumption requires that the realized outcome is extreme: if we define $L$ to indicate a set of outcomes $\left\{L_{1}, \ldots, L_{N}\right\}$, then this assumption requires that $S\left(\omega_{t}, H\right)>\bar{S}$ implies $S\left(\omega_{t}, H\right)>$ $\sum_{i=1}^{N}\left[p_{\tau-1}^{L_{i}} /\left(1-p_{\tau-1}^{H}\right)\right] S\left(\omega_{t}, L_{i}\right)$. Appendix C.2 relaxes the assumption that the realized outcome is extreme.
} 


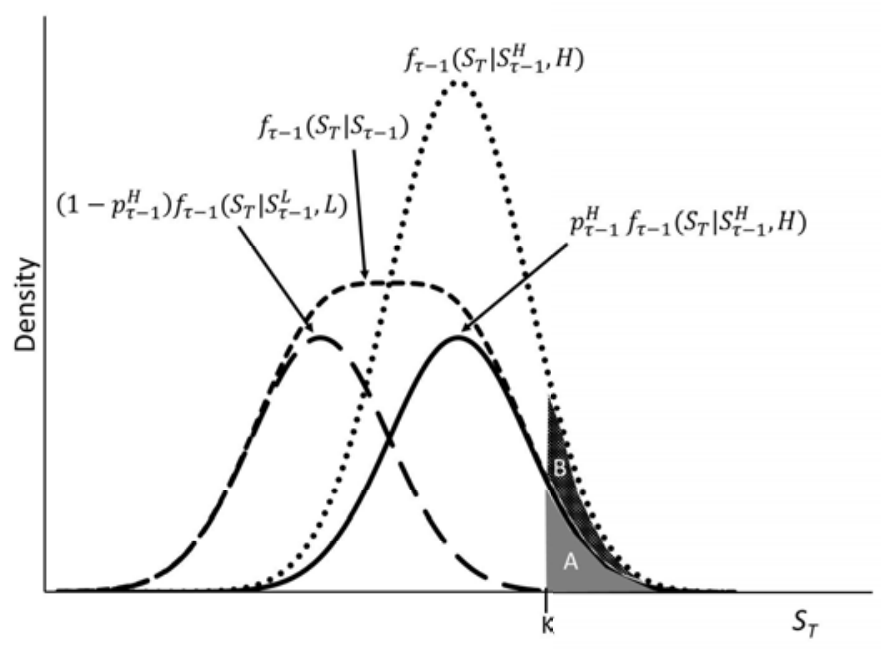

Figure 1: Illustration of how changes in option prices identify the probability $p_{\tau-1}^{H}$ when event $H$ is realized at time $\tau$.

line $\left.f_{\tau-1}\left(S_{T} \mid S_{\tau-1}^{H}, H\right)\right)$ and the distribution conditional on the counterfactual event occurring (the solid line $f_{\tau-1}\left(S_{T} \mid S_{\tau-1}^{L}, L\right)$ ). The value of a call option with strike $K$ is the discounted expected value of the difference between the time $T$ stock price and $K$, conditional on the stock price being in the area labeled A. Once the event occurs, the density of stock prices at the expiration date becomes the dotted line $f_{\tau-1}\left(S_{T} \mid S_{\tau-1}^{H}, H\right)$ and the option's value is calculated as the integral over the larger area $A+B$. If, as depicted, the distribution $f_{\tau-1}\left(S_{T} \mid S_{\tau-1}^{L}, L\right)$ contains very little mass above $K$, the jump in the option price between date $\tau-1$ and $\tau$ identifies the extent to which the distribution of stock prices conditional on the realized outcome $\left(f_{\tau-1}\left(S_{T} \mid S_{\tau-1}^{H}, H\right)\right)$ was downweighted by the probability $p_{\tau-1}^{H}$ of that outcome.

In Figure 1, the bias of this approach is very close to zero for the indicated $K$. For smaller $K, f_{\tau-1}\left(S_{T} \mid S_{\tau-1}^{L}, L\right)$ may have nontrivial mass in region A. In this case, the change in the price of the option reflects both the resolution of uncertainty surrounding the event and the loss of this unobserved probability mass. The possibility of unobserved probability mass drives the bias term in equation (5).

Equation (5) further shows that the bound $\bar{p}$ will be especially tight when $p_{\tau-1}^{H}$ is large. This is precisely the case in which standard event studies suffer arbitrarily large biases (see equation (2)) and therefore is the case in which a tight bound is most needed. The bias vanishes as $p_{\tau-1}^{H}$ grows both because $1-p_{\tau-1}^{H}$ shrinks and because $S_{\tau-1}^{L}$ shrinks (for given observables $S_{\tau-1}$ and $S_{\tau-1}^{H}$ ). In Figure 1, large 
$p_{\tau-1}^{H}$ corresponds to a case in which the distribution conditional on $L$ receives little weight. The long-dashed distribution then has little effect on the price of the option just before the event occurs.

Put options can also recover the event probability, which is useful when an event reduces the price of the underlying asset. Trivially adapting equations (3) through (5), $\bar{p}$ is again the ratio of the option price the day before the event to the option price the day before the event if the event outcome were already known. The bias is small if $P_{\tau-1, T}^{L}\left(S_{\tau-1}^{L}, K\right)$, the value of the put option under the counterfactual outcome, is small. However, now this condition is more likely to hold when an event reduces the stock price. ${ }^{16}$

Put options are therefore useful when an event reduces the price of an option's underlying asset, while call options are useful when an event increases the price of an option's underlying asset. However, much work has conjectured that out-ofthe-money put options carry a premium because they offer protection against lowprobability crashes. ${ }^{17}$ The possibility of such disasters is plausibly independent of the event outcome. In that case, deep out-of-the-money put options may retain much of their value even if event outcome $L$ occurs. The bias in a version of equation (5) using puts therefore does not converge to zero as $K$ becomes small. ${ }^{18}$ Further, if the value of the deepest out-of-the-money put options is primarily driven by disaster risk that is independent of the event outcome, then the bias from estimating $p_{\tau-1}^{H}$ may actually increase as the strike price falls. It is no longer clear which strikes should provide the tightest bound.

Estimating $\bar{p}$ may therefore be most informative when the realized event increases

\footnotetext{
${ }^{16}$ Again applying standard arbitrage bounds, we have $\bar{p} \geq p_{\tau-1}^{H}$. If event $H$ decreases stock prices in sufficiently extreme states of the world (i.e., if there exists $\underline{S}$ such that $S\left(\omega_{t}, L\right)<\underline{S}$ implies $\left.S\left(\omega_{t}, H\right)<S\left(\omega_{t}, L\right)\right)$ and if, in addition, sufficiently low prices would not be possible following event $L$ (i.e., if $f_{\tau-1}\left(S_{T} \mid S_{\tau-1}^{L}, L\right) \rightarrow 0$ as $S_{T}$ approaches some small positive value), then the arbitrage bound $P_{\tau-1, T}^{L}\left(S_{\tau-1}^{L}, K\right) \geq 0$ holds exactly as $K$ becomes small. In that case, the bias in the version of equation (5) with put options converges to zero for some sufficiently small $K$. The ratio of the observed and counterfactual put option prices at time $\tau-1$ then accurately recovers $p_{\tau-1}^{H}$.

${ }^{17}$ Since the 1987 stock market crash, out-of-the-money put options on the S\&P index have carried a premium (identified via the implied volatility "smirk") reflecting an implied risk-neutral distribution that heavily weights the possibility of a crash (e.g., Rubinstein, 1994; Jackwerth and Rubinstein, 1996; Bates, 2000). Kelly et al. (2016) find that the crash or tail-risk premium can become especially large around political events, such as the elections we consider in our applications below. Others have explored whether the possibility of rare disasters can explain the equity premium puzzle (e.g., Rietz, 1988; Barro, 2006; Barro and Ursúa, 2012).

${ }^{18} \mathrm{With}$ respect to footnote 16 , it may in fact not be true that $f_{\tau-1}\left(S_{T} \mid S_{\tau-1}^{L}, L\right) \rightarrow 0$ as $S_{T}$ approaches some small positive value.
} 
a firm's stock price. In that case, researchers can estimate the event's risk-neutral probability from call options, for which the bias is more likely to decrease monotonically in observed strike prices and plausibly vanishes for sufficiently large strike prices. $^{19}$

\subsection{Using the Change in Expected Variance}

The previous method of estimating the priced-in event probability $p_{\tau-1}^{H}$ relied on changes in the tail of the distribution of $S_{T}$, as reflected in option prices. We now derive a second method of estimating the priced-in probability, using changes in the expected variance of stock prices. This method identifies the event probability under a different set of circumstances, now requiring advance knowledge of the date that the event will happen and requiring that the expected variance of the stock price in the days immediately after an event be independent of the event's realization.

Assuming that market participants know that the event will occur at time $\tau$, the time $\tau-1$ variance of the time $\tau$ stock price includes both the variance coming from the resolution of the event and the variance coming from the evolution of $\omega_{\tau}$. Conditioning on $\omega_{\tau}$, the variance generated by the event itself is:

$$
\operatorname{Var}_{\tau-1}\left[S_{\tau} \mid \omega_{\tau}\right]=p_{\tau-1}^{H}\left(S_{\tau-1}^{H}-S_{\tau-1}\right)^{2}+\left(1-p_{\tau-1}^{H}\right)\left(S_{\tau-1}^{L}-S_{\tau-1}\right)^{2} .
$$

Using equation (1), the variance generated by the event itself can be written as:

$$
\operatorname{Var}_{\tau-1}\left[S_{\tau} \mid \omega_{\tau}\right]=\frac{p_{\tau-1}^{H}}{1-p_{\tau-1}^{H}}\left(S_{\tau-1}^{H}-S_{\tau-1}\right)^{2},
$$

This conditional variance is a function only of the event-induced jump in stock prices and the market's probability of the event as of $\tau-1$. This suggests that we can recover $p_{\tau-1}^{H}$ if we can estimate the variance generated by the event.

Now consider the unconditional variance of stock prices from time $\tau-1$ to time $\tau$. Temporarily fixing the one-day gross risk-free rate to $R_{\tau-1, \tau}=1$, Appendix D.1 shows that

$$
\operatorname{Var}_{\tau-1}\left[S_{\tau}\right]=\operatorname{Var}_{\tau-1}\left[S_{\tau} \mid \omega_{\tau}\right]+p_{\tau-1}^{H} \operatorname{Var}_{\tau-1}\left[S_{\tau}^{H}\right]+\left(1-p_{\tau-1}^{H}\right) \operatorname{Var}_{\tau-1}\left[S_{\tau}^{L}\right] .
$$

\footnotetext{
${ }^{19}$ Of course, the deeper out-of-the-money call options' value could be driven by unusually favorable circumstances that make the event irrelevant, but it is more likely that an event will move stock prices in both slightly and strongly favorable scenarios than that an event will move stock prices in both slightly and severely unfavorable scenarios.
} 
The first term on the right-hand side is the conditional variance from equation (6), generated by resolution of the event uncertainty. The second and third terms capture the expectation of the variance induced by the resolution of $\omega_{t}$.

Subtracting $\operatorname{Var}_{\tau-1}\left[S_{\tau}^{H}\right]$ from each side of equation (7), substituting from equation (6), and rearranging, we find:

$$
\frac{p_{\tau-1}^{H}}{1-p_{\tau-1}^{H}}=\frac{\operatorname{Var}_{\tau-1}\left[S_{\tau}\right]-\operatorname{Var}_{\tau-1}\left[S_{\tau}^{H}\right]}{\left(S_{\tau-1}^{H}-S_{\tau-1}\right)^{2}}+\left(1-p_{\tau-1}^{H}\right) \frac{\overbrace{\left(\operatorname{Var}_{\tau-1}\left[S_{\tau}^{H}\right]-\operatorname{Var}_{\tau-1}\left[S_{\tau}^{L}\right]\right)}^{\Delta V a r}}{\left(S_{\tau-1}^{H}-S_{\tau-1}\right)^{2}} .
$$

This formulation relates the event probability on the left-hand side to a function of the event's effect on stock prices and its effect on the variance of the stock price, both of which are in the first term on the right-hand side and can be estimated. The second term on the right-hand side is proportional to the difference in the variance of $\omega_{t}$ under realized and counterfactual events, which we label $\Delta V a r$. If the event outcome does not affect the variance of the stock price, then $\Delta V a r$ is equal to zero and this second term vanishes. In that case, the change in variance at the event and the change in the stock price at the event together identify the priced-in event probability.

If we had a portfolio of options that could replicate $\operatorname{Var}_{\tau-1}\left[S_{\tau}\right]$, then we could potentially construct a similar replicating portfolio for $\operatorname{Var}_{\tau-1}\left[S_{\tau}^{H}\right]$ by applying event study methods and then use equation (8) to recover an estimate of $p_{\tau-1}^{H}$. Martin (2017) provides a critical result. He constructs the replicating portfolio for a related object, a "simple variance swap" ${ }^{20}$ The variance strike $V_{\tau-1, T}$ that sets the value of a simple variance swap to zero is:

$$
V_{\tau-1, T}=E_{\tau-1}\left[\sum_{j=0}^{T-\tau}\left(\frac{S_{\tau+j}-S_{\tau+j-1}}{\tilde{R}_{\tau-1, \tau+j-1} S_{\tau-1}}\right)^{2}\right]
$$

where expectations are, as elsewhere, taken under the risk-neutral measure and where $\tilde{R}_{t, y}$ is the net-of-dividend gross rate from time $t$ to $y .{ }^{21}$ Martin (2017) prices the simple variance swap under the assumptions of a constant interest rate, a constant

\footnotetext{
${ }^{20}$ The long position in a variance swap pays a fixed amount (the "strike") at some future time $T$ in exchange for payments linked to the realized variance of a stock's price between times $t$ and $T$. The time $t$ variance swap rate is the strike that sets the value of the swap to 0 at time $T$. This strike is equal to the risk-neutral expected variance between times $t$ and $T$.

${ }^{21}$ Note that $\tilde{R}_{\tau-1, y} S_{\tau-1}$ is the time $\tau-1$ forward price of $S_{y}$.
} 
dividend rate, and small timesteps, without assuming away the possibility of jumps. ${ }^{22}$ Martin (2017) shows that

$V_{\tau-1, T}=\frac{2 R_{\tau-1, T}}{\left[\tilde{R}_{\tau-1, T} S_{\tau-1}\right]^{2}}\left\{\int_{0}^{\tilde{R}_{\tau-1, T} S_{\tau-1}} P_{\tau-1, T}\left(S_{\tau-1}, K\right) \mathrm{d} K+\int_{\tilde{R}_{\tau-1, T} S_{\tau-1}}^{\infty} C_{\tau-1, T}\left(S_{\tau-1}, K\right) \mathrm{d} K\right\}$.

The variance strike $V_{\tau-1, T}^{H}$ for a conditional simple variance swap can be recovered using equation (9) and option prices that are estimated to hold under the realized outcome $H$.

The following proposition relates the event probability $p_{\tau-1}^{H}$ to the values of simple variance swaps $V_{\tau-1, T}$ and $V_{\tau-1, T}^{H}$ :

Proposition 1. Define

$$
\tilde{V} \triangleq\left(S_{\tau-1}\right)^{2} V_{\tau-1, T}-\left(S_{\tau-1}^{H}\right)^{2} V_{\tau-1, T}^{H}, \quad \tilde{p} \triangleq \frac{\tilde{V}}{\tilde{V}+\left[2 \tilde{R}_{\tau-1, \tau}-1\right]\left[S_{\tau-1}^{H}-S_{\tau-1}\right]^{2}} .
$$

Then:

1. $\tilde{p} \rightarrow p_{\tau-1}^{H}$ as either $\left[S_{\tau-1}^{H}\right]^{2} V_{\tau-1, T}^{H}-\left[S_{\tau-1}^{L}\right]^{2} V_{\tau-1, T}^{L} \rightarrow 0$ or $p_{\tau-1}^{H} \rightarrow 1$.

2. If $\tilde{V}>0$, then $p_{\tau-1}^{H} \geq \tilde{p}$ if and only if $\left[S_{\tau-1}^{L}\right]^{2} V_{\tau-1, T}^{L} \leq\left[S_{\tau-1}^{H}\right]^{2} V_{\tau-1, T}^{H}$.

3. If $\tilde{V}<0$, then $\tilde{p}$ is an uninformative bound on $p_{\tau-1}^{H}$.

Proof. See appendix.

The proposition defines an estimator $\tilde{p}$ of $p_{\tau-1}^{H}$. The first result establishes that $\tilde{p}$ becomes an arbitrarily good approximation to $p_{\tau-1}^{H}$ as the difference in the (scaled) conditional simple variance swap rates goes to zero $\left(\left[S_{\tau-1}^{H}\right]^{2} V_{\tau-1, T}^{H}-\left[S_{\tau-1}^{L}\right]^{2} V_{\tau-1, T}^{L} \rightarrow\right.$

\footnotetext{
${ }^{22}$ The pricing of variance swaps dates back to the early 1990s, but most literature assumes that the underlying stock price cannot jump. See Carr and Lee (2009) for a review. However, we are here interested precisely in the possibility of jumps. Jiang and Tian (2005) and Carr and Wu (2009) describe the approximation error induced by jumps. We follow the approach of Martin (2017), who redefines the variance to be exchanged so that very small stock prices do not cause the payoff to go to infinity. Martin (2017) assumes European options, yet we observe American options in the empirical application. To minimize the importance of this distinction, we will drop firms with high dividend yields, will use options with short maturities, and will clean options of early exercise premia.
} 
0 ) or as $p_{\tau-1}^{H} \rightarrow 1$. Even if the difference in the conditional simple variance swap rates is not small, we again have a good approximation in the case of large $p_{\tau-1}^{H}$, which, from equation (2), is when the full event effect is most sensitive to $p_{\tau-1}^{H}$. The second result establishes that $\tilde{p}$ is a lower (upper) bound on $p_{\tau-1}^{H}$ when the scaled conditional simple variance swap rate is smaller (larger) under the counterfactual event outcome $L$ than under the realized event outcome $H$. The intuition for the result tracks that already given for equation (8), with $\left[S_{\tau-1}^{H}\right]^{2} V_{\tau-1, T}^{H}-\left[S_{\tau-1}^{L}\right]^{2} V_{\tau-1, T}^{L} \rightarrow 0$ serving as the analogue of the difference in the variance resulting from $\omega_{\tau}$ under the different potential event outcomes. ${ }^{23}$ As $p_{\tau-1}^{H} \rightarrow 1$, the possibility that $\left[S_{\tau-1}^{L}\right]^{2} V_{\tau-1, T}^{L}$ differs from $\left[S_{\tau-1}^{H}\right]^{2} V_{\tau-1, T}^{H}$ becomes irrelevant.

The sign of $\tilde{V}$ plays a critical role in Proposition 1 , where $\tilde{V}$ is a metric readily constructed from observed option prices and from event study estimates. If $\tilde{V}>0$, then uncertainty (as measured by the scaled conditional variance swap rates) is reduced by learning the event outcome. This is the standard case, which we implicitly assumed in discussing equation (8). In contrast, if $\tilde{V}<0$, then the variance conditional on event outcome $H$ is greater than the variance of the full compound lottery. From equation (7), this can happen only if expected variance is sufficiently greater under the realized event outcome than under the counterfactual event outcome. In this case, expected variance is far from independent of the event outcome and $\tilde{p}$ provides an uninformative bound on $p_{\tau-1}^{H}$, being either less than zero or greater than 1 .

In sum, the critical condition for $\tilde{p}$ to recover $p_{\tau-1}^{H}$ is that the expected variance between day $\tau$ and the option expiration date $T$ be independent of the event outcome. Previous approaches to recovering event probabilities with parametric option pricing models implicitly imposed an analogous restriction in addition to other distributional assumptions (e.g., Gemmill, 1992; Carvalho and Guimaraes, 2018). This new approach is therefore a direct generalization of prior literature.

\subsection{Comparing the Two Estimators}

We have developed two new estimators of the risk-neutral probability of an event. Both estimators are model-free, in contrast to the prior literature that recovers event probabilities from option prices by assuming that stock prices evolve according to specific parametric processes. The first estimator $(\bar{p})$ requires that some options that are valuable when the realized event happens would have been worth very little if other events had happened. The second estimator $(\tilde{p})$ requires that the expected

\footnotetext{
${ }^{23}$ If there are multiple possible event outcomes, then $\left[S_{\tau-1}^{L}\right]^{2} V_{\tau-1, T}^{L}$ becomes the expected postevent variance conditional on event $H$ not occurring.
} 
variance of the stock price process over a post-event window not be sensitive to the realization of the event.

The strengths of the estimator $\bar{p}$ are that it is straightforward to compute, that it does not require market agents to anticipate that the event was going to occur on a particular date, and that we know which types of options should yield the tightest bound. In contrast, the estimator $\tilde{p}$ requires approximating an integral over option prices, requires market agents to know the event's date at least one day ahead of time, and imposes an identifying assumption that is difficult to test (but may not be especially restrictive when the time to expiration is short). In particular, the integral approximation becomes poorer when liquidly traded options' strike prices become less dense and/or cover a narrower interval. In this case, we may obtain only a noisy estimate of $\tilde{p}$.

However, the estimator $\tilde{p}$ can perform well in contexts in which the estimator $\bar{p}$ may yield only a loose bound. First, some events will not affect firms with many deep out-of-the-money options that are liquidly traded. Second, some realized events will not be extreme. Appendix C.2 shows that the bound obtained from $\bar{p}$ cannot become arbitrarily tight for such "middle" events. In contrast, $\tilde{p}$ does not depend on the realized event being extreme. Third, some events will only reduce firms' value. In these cases, researchers must use put options to estimate $\bar{p}$, but, as discussed above, we might expect greater bias when estimating $\bar{p}$ from put options.

In sum, the two estimators are complementary. Since they rely on distinct assumptions, obtaining similar results from both approaches should increase researchers' confidence in having properly recovered an event's probability.

\section{Empirical Approach}

Both of our approaches to recovering the priced-in probability of an event require estimating what the price of an option would have been if the event's realization had been known a bit earlier. This is the standard event study identification challenge.

We obtain stock prices, quarterly dividends, and earnings dates from Compustat. We obtain equity options data from OptionMetrics, using all firms available in IvyDB US. We calculate an option's price as the average of its closing bid and its closing ask. In our OPEC application, we study options on crude oil futures. $S_{t}$ then represents the price of the underlying future. We obtain oil futures and options data from Intercontinental Exchange.

For both estimators, we limit the sample to the nearest major expiration date so that the distinction between European-style and American-style options is less 
important (see Appendix C.1). ${ }^{24}$ For a similar reason, we drop firms with a quarterly dividend yield greater than $2 \%$ over the estimation window (e.g., Dubinsky et al., 2019). Previous work has shown that options prices respond to earnings announcements (e.g., Patell and Wolfson, 1979, 1981; Dubinsky et al., 2019), so we limit the sample to firms that do not have an earnings announcement in a 3-day window around the event. Finally, we drop firms whose stock price falls below $\$ 5$ at any point in either the estimation or event windows (e.g., Dubinsky et al., 2019).

Using these data, we describe our approaches to estimating $\bar{p}$ and $\tilde{p}$ in turn, including additional, theoretically motivated restrictions designed to recover tight bounds on the priced-in event probability.

\subsection{Estimating $\bar{p}$ from Out-of-the-Money Options}

We first describe how we estimate $\bar{p}$ in the equity option application, where we observe options on many firms. We then describe how we adjust our empirical approach in the oil market application, where we observe a dense set of strikes on a single commodity.

Consider the case with options on many firms exposed to the same event, with firms indexed by $i$. We estimate $\bar{p}$ from the following regression: ${ }^{25}$

$$
\ln \left(C_{i K(t-1)} / C_{i K t}\right)=\alpha_{i K}+\beta \text { Event }_{t}+\theta_{i K} X_{i t}+\varepsilon_{i K t},
$$

where we simplify the call option price notation to $C_{i K t}$. Event $t_{t}$ is a indicator variable for the day the event information is realized. $X_{i t}$ is a vector of controls, which includes time to expiration and its square, indicator variables for the days before and after the event, and indicator variables for a three-day window around earnings announcements. ${ }^{26}$

The prices of observations with greater liquidity and lower transaction costs provide more precise measures of contemporary information. We therefore weight equation (11) by the inverse of the relative bid-ask spread (Madhavan, 2000; Vayanos and

\footnotetext{
${ }^{24}$ Equity options in our data overwhelmingly expire on the third Friday of the month. There are some options that expire on other dates within the month, but we focus our analysis on the major expiration dates because the other expiration dates are less liquid. We use the first major expiration date that is at least a week past the end of our estimation window (see Beber and Brandt, 2006; Kelly et al., 2016).

${ }^{25}$ We use the log of the option price ratio because we find that log-changes in option prices are approximately normally distributed.

${ }^{26}$ We do not control for the market index. Because we analyze substantial events that may have affected that index, controlling for it could absorb the desired event effect. Controlling for the market index may be appropriate in other applications.
} 
Wang, 2013) averaged over days $t$ and $t-1$. We assign a weight of zero if either day has a bid of zero. We run the regression on trading days that are within 100 days before the event and all trading days after the event up to 7 days before the option's expiration date (see Beber and Brandt, 2006). Standard errors are clustered by firm and by date. We run an analogous regression when we examine puts.

We estimate $\bar{p}$ by predicting $C_{i K(\tau-1)} / C_{i K(\tau-1)}^{H}$ from $\hat{\beta}$, comparing the option price on the day before the event to what the option price would have been if the event outcome had been known but nothing else had changed. This gives us $\bar{p}=\exp (\hat{\beta})$. We do not let $\beta$ vary across firms because the event probability should here not vary across firms, although this constraint could be relaxed in other applications. ${ }^{27}$

The regression in equation (11) will recover an upper bound on the event probability. The bound is tight if $C_{\tau-1, T}^{L}\left(S_{\tau-1}^{L}, K\right)$ is small, but $C_{\tau-1, T}^{L}\left(S_{\tau-1}^{L}, K\right)$ is unobservable. We therefore make a few additional restrictions on the set of options we analyze in order to recover a tight bound on the event probability without knowledge of $C_{\tau-1, T}^{L}\left(S_{\tau-1}^{L}, K\right)$. These restrictions all leverage theoretically motivated insights about how the bias in equation (5) varies with observables.

First, we saw in Section 3.1 that deeper out-of-the-money options will generate tighter bounds than closer-to-the-money options, assuming all are liquid. ${ }^{28}$ Our preferred specifications therefore limit the sample to the deepest out-of-the-money liquid option for each firm. ${ }^{29}$

Second, following Section 3.1, we should use put options for firms whose stock price declines with the event, but estimates based on put options will be especially biased if those options account for a disaster risk that is independent of the event. We assess firms' response to the event via firm-by-firm traditional event studies:

$$
\ln \left(S_{i t} / S_{i(t-1)}\right)=\gamma_{i 1}+\gamma_{i 2} \text { Event }_{t}+\gamma_{i 3} X_{i t}^{S}+\varepsilon_{i t},
$$

where $S_{i t}$ is the closing stock price for firm $i$ on trading date $t, X_{i t}^{S}$ includes the earning announcement and event controls from before, and standard errors are clustered by

\footnotetext{
${ }^{27}$ By absence of arbitrage, all firms exposed to the same event must have the same risk-neutral probability of the event. Heterogeneous beliefs about the probability of an event could affect that market probability but should not lead it to differ across firms. Probabilities of composite events (such as complex court rulings) can vary by firm if exposure to various components of the event differs by firm.

${ }^{28}$ As noted earlier, this effect is especially strong when a realized event increases stock prices because the empirical researcher then analyzes call options, whose value does not include a hedge against disasters.

${ }^{29}$ We define the set of sufficiently liquid strikes according to the method used in constructing the VIX: we use all strikes with nonzero bids between the forward price and the point at which two strikes in a row have bids of zero. See Cboe (2019).
} 
firm and by date. ${ }^{30}$ We use our estimate of $\gamma_{i 2}$ to restrict our analysis to firms whose stock prices were positively affected by the event $\left(\hat{\gamma}_{i 2}>0\right)$ and thus to call options.

Finally, we restrict attention to firms that are strongly affected by the event. A firm that is unaffected by an event does not provide information about $p_{\tau-1}^{H}$. Moreover, a firm will, all else equal, generate a tighter bound on the event probability if its stock price is especially sensitive to the event: for a given probability of the event, a larger jump in the stock price at the event $\left(S_{\tau-1}^{H}-S_{\tau-1}\right)$ implies that the counterfactual value of the stock $\left(S_{\tau-1}^{L}\right)$ is low and thus that the counterfactual value of the option $\left(C_{\tau-1}^{L}\right)$ is likely to be small. ${ }^{31}$ We use the t-statistic on $\hat{\gamma}_{i 2}$ in equation (12) to limit the sample to firms that were especially affected by the event. This limitation should reduce bias but also increases the variance of our estimate by limiting us to fewer option prices. We provide results with increasingly strict t-statistic cutoffs to show how $\bar{p}$ and its standard error vary with the severity of this restriction.

We adapt our approach slightly for the oil market application, where we have only a single underlying asset but substantially greater density of strike prices. We seek to use information at more strikes while still focusing on strikes that are both farther from the money and relatively liquid. We therefore estimate the event's effect on option prices by fitting a spline across strikes in the event-day effect:

$$
\ln \left(C_{K(t-1)} / C_{K t}\right)=\beta_{0} \text { Event }_{t}+\sum_{j=1}^{J} \beta_{j} \min \left(K-\mu_{j-1}, \mu_{j}-\mu_{j-1}\right) \text { Event }_{t}+\varepsilon_{K t},
$$

where the $\mu_{j}$ are knots that evenly divide the oil option strikes into $J$ evenly sized groups (with $\mu_{0}=0$ ). We fit splines with $J=10$ knot points. ${ }^{32}$ The variables in the vector $X_{t}$ control for other OPEC meetings that occur in a given meeting's estimation window, for splines in the day before and day after the meeting effect, and for time to expiration and its square. Because we do not observe bid and ask prices, we weight observations by average open interest across days $t$ and $t-1$. We take the minimum of the estimated spline and its standard error as our estimate of $\bar{p}$.

\subsection{Estimating $\tilde{p}$ from Synthesized Variance Swaps}

Now consider estimating $\tilde{p}$. Begin by considering the probability $\tilde{p}_{i}$ implied by options on firm $i$. Our estimate of $\tilde{p}$ (from equation (10)) requires the variance swap

\footnotetext{
${ }^{30}$ We use a 200-day estimation window (180 days before and 20 days after the event).

${ }^{31}$ This corresponds to the case in which $f_{\tau-1}\left(S_{T} \mid S_{\tau-1}^{L}, L\right)$ in Figure 1 has little mass above $K$.

${ }^{32}$ Appendix B shows that our estimates are not sensitive to the number of knot points.
} 
rate on the day before the event $\left(V_{i(\tau-1, T)}\right)$ and the counterfactual variance swap rate if the event's outcome were already known $\left(V_{i(\tau-1, T)}^{H}\right)$. Equation (9), from Martin (2017), shows that calculating $V_{i(\tau-1, T)}$ requires integrating call and put option prices over the domain of strikes. However, we observe option prices only at discrete strikes. We discretize the integral and calculate the forward price by adapting the methodology used to construct the familiar VIX index (see Cboe, 2019). ${ }^{33}$ We use $R_{\tau-1, T}$ from a daily version of the 3 -month LIBOR rate. To calculate $V_{i(\tau-1, T)}^{H}$, we use counterfactual option prices predicted from a regression like (11), modified to allow the event effect $\left(\beta_{i K}\right)$ to vary by firm and strike. ${ }^{34}$ Similarly, we recover $S_{i(\tau-1)}^{H}$ from a regression that adds heterogeneity in the event effect by firm and strike to equation (12). The observed forward price and $S_{i(\tau-1)}$ together imply $\tilde{R}_{i(\tau-1, \tau)}$ (see footnote 21).

Following Martin (2017), our approach to discretizing the integral avoids using pricing models at any step. The variance swap pricing literature often more finely discretizes the integral by converting option prices to implied volatilities, interpolating implied volatility on a fine grid between observed strikes, and then converting back to option prices (e.g., Carr and $\mathrm{Wu}, 2009)$. This alternate approach has the advantages of stripping early exercise premia from option prices and more finely approximating the integral, but it has the disadvantage of using pricing models to convert to and from implied volatility. Appendix A.2 describes this alternate approach and shows that it yields results similar to our baseline ones.

We estimate $\tilde{p}$ as the average of the $\tilde{p}_{i}$. Following Proposition 1, we drop firms for which the central estimate of $\tilde{V}_{i}$ is negative. We calculate the standard error of $\tilde{p}$ from the generalized method of moments. ${ }^{35}$ Estimated covariance matrices are

\footnotetext{
${ }^{33}$ For equities, we adapt the VIX methodology (Cboe, 2019) to drop options with a bid of zero on either day $\tau-1$ or day $\tau$ as well as some others likely to be illiquid. We drop any firms that do not have at least three strikes surviving this restriction. Appendix A.2 shows that results are not sensitive to tightening this requirement. For commodities, we drop all options with open interest below 50 and all strikes that are at least as deep out-of-the-money as the first strike at which the price is constant for two strikes in a row.

${ }^{34}$ As in Section 4.1, we weight by the inverse of the relative bid-ask spread averaged over days $t-1$ and $t$, with a weight of zero assigned if either day has a bid of zero. When calculating counterfactual stock prices and option implied volatilities, we use a second-order Taylor expansion that adjusts for the standard error of the estimated event effect.

${ }^{35}$ We stack the moment conditions underlying all regressions of the forms (11) and (12) into a single system and add the moment conditions $\tilde{p}_{i}-\tilde{p}=0$. To apply those last moment conditions, we express each counterfactual option price in a version of equation (9) in terms of the estimated coefficients from the regressions (11) and (12). The system is over-identified when there is more than one firm. In future work, we will estimate the regressions and $\tilde{p}$ simultaneously, including with a two-step estimator, and we will explore running event studies on $V$ directly. When there is
} 
clustered by date.

\section{Applications}

We apply our new methods to two high-stakes settings. The first setting, the 2016 U.S. election, is one in which we have a rough idea of the probability from prediction markets and polling data. It serves to validate our approach. The second setting is the regular meetings of the Organization of the Petroleum Exporting Countries. We use our methods to understand OPEC's ability to influence world oil prices through the rise of U.S. oil production and show how this understanding changes after controlling for market anticipation of OPEC meeting outcomes.

\subsection{The 2016 U.S. Election}

On Tuesday November 8, 2016, Donald Trump was elected President of the United States and the Republican party captured both chambers of Congress. ${ }^{36}$ This extreme outcome was widely surprising. On the morning of November 8, the prediction market PredictIt gave Trump a $22 \%$ chance of winning, gave Republicans a $41 \%$ chance of controlling the Senate, and gave Republicans a 16\% chance of controlling the presidency and both chambers of Congress. The polling-driven New York Times' Upshot forecast gave Trump a $15 \%$ chance of winning, whereas the polling-driven FiveThirtyEight forecasts gave him a $28-29 \%$ chance of winning. ${ }^{37}$ Both forecasts gave Republicans around a 50\% chance of controlling the Senate. PredictWise, which uses both prediction market data and polling data, gave Trump a $12 \%$ chance of winning, gave Republicans a 33\% chance of controlling the Senate, and gave Republicans around a $94 \%$ chance of controlling the House of Representatives. Using conditional probabilities implied by the PredictIt contracts, the chance of a Republican sweep was $13 \%$ according to the Upshot, $26 \%$ according to FiveThirtyEight, and $7 \%$ ac-

only one firm (or commodity), we stack the regression moment conditions to estimate a covariance matrix for the regression coefficients and apply the delta method to $\tilde{p}_{i}$.

${ }^{36}$ The country learned of this outcome in between markets' close on November 8 and their opening on November 9. This election is particularly attractive for validating our methods because it was an extreme outcome that was largely known by the time markets closed on the day after the election. Other elections can be more ambiguous. For instance, the 2008 election of Barack Obama occurred in tandem with critical Senate elections that were not resolved for some time afterward.

${ }^{37}$ Whereas prediction markets plausibly give a risk-neutral probability, polling-driven estimates target an objective probability. It is unclear whether the risk-neutral probability of the realized election outcome should be greater or less than the objective probability. 
cording to PredictWise. ${ }^{38}$ Finally, the prediction market Betfair gave Trump a $20 \%$ chance of winning and the bookmakers Paddy Power and Ladbroke's odds implied that Trump had a $22 \%$ and $24 \%$ chance of winning, respectively. Using the range of Senate probabilities above, these three sources imply that the chance of a Republican sweep was between $12 \%$ and $21 \%$. In sum, the various markets and models imply that the chance of a Republican sweep was somewhere between $7 \%$ and $26 \%$.

Table 1 reports our estimates of the probability of the realized 2016 election outcome with our different approaches. ${ }^{39}$ The top panel reports the $\bar{p}$ obtained from out-of-the-money options, as described in Section 4.1. The first column does not impose any of the theoretically motivated restrictions. As expected, this estimate is subject to severe upward bias: we estimate an unreasonable probability above 1. The second column restricts attention to the deepest out-of-the-money options that are sufficiently liquid. Again, this estimate is biased upwards with an estimated probability above 1 . The third column aims to further reduce bias by restricting attention to specifications with call options: it drops firms for which the election lowered stock prices $\left(\hat{\gamma}_{i 2} \leq 0\right)$. The estimated probability falls only slightly, to 0.60 .

The remaining columns limit the sample to firms with sufficiently large t-statistics on $\hat{\gamma}_{i 2}$. The fourth column drops those firms which were either nearly unaffected by the election (and thus reveal nothing about $p_{\tau-1}^{H}$ ) or not strongly affected by the election (and thus biased upwards). The estimated probability falls substantially, to 0.39 . The remaining columns tighten this restriction further, with the estimated probability appearing to converge around $0.12 .{ }^{40}$ This estimated probability is well within the range of pre-election probabilities surveyed above and is quite close to the PredictIt contract for full Republican control.

One might be concerned that, by attending only to firms with large t-statistics, we select for firms that had something unexpected happen to them, whether the

\footnotetext{
${ }^{38}$ PredictIt implies that the probability of Trump winning conditional on Republicans winning the Senate was 0.39. Calculations for other sources assume that the ratio of that conditional probability to the unconditional probability of Trump winning was constant across models and markets. We assume that Republicans would not win the Senate without also winning the House of Representatives, which was a common belief at the time.

${ }^{39}$ Our methods require that some number of liquidly traded firms be sensitive to the election outcome. The 2016 election clearly passes this test. Appendix A shows that most firms' stocks jumped in extremely unusual fashion: $71 \%(10 \%)$ of firms had t-statistics of magnitude greater than 10 (50), which should very rarely happen by chance. The large number of firms affected by the same event is a good setting in which to test our methods. The last row of the top panel of Table 1 reports the combined volume on the election day and the day after the election for the options used in each estimation.

${ }^{40}$ If we allowed firms with $\hat{\gamma}_{i 2}<0$ and imposed a cutoff in the absolute value of the t-statistic, then the estimated probability would be around 2 percentage points larger in each of these columns.
} 
Table 1: Estimated Probability for 2016 Election Outcome

\begin{tabular}{lccccccc}
\hline & $\begin{array}{c}\text { Standard } \\
\text { Restrictions }\end{array}$ & $\begin{array}{c}\text { Extreme } \\
\text { Strikes }\end{array}$ & $\begin{array}{c}\text { Positive } \\
\text { Events }\end{array}$ & $\begin{array}{c}\text { t-statistic } \\
>25\end{array}$ & $\begin{array}{c}\text { t-statistic } \\
>50\end{array}$ & $\begin{array}{c}\text { t-statistic } \\
>75\end{array}$ & $\begin{array}{c}\text { t-statistic } \\
>100\end{array}$ \\
\hline $\begin{array}{l}\text { Out-of-the-Money Options } \\
\text { Approach: }\end{array}$ & & & & & \\
Probability & 1.032 & 1.062 & 0.602 & 0.387 & 0.221 & 0.132 & 0.119 \\
Standard Error & $(0.003)$ & $(0.005)$ & $(0.007)$ & $(0.006)$ & $(0.007)$ & $(0.006)$ & $(0.024)$ \\
\# Firms & 2,629 & 2,595 & 1,835 & 764 & 188 & 43 & 10 \\
\# Options & 79,885 & 5,122 & 1,835 & 764 & 188 & 43 & 10 \\
\# Option-Days & $2,979,681$ & 214,576 & 77,569 & 32,057 & 7,624 & 1,897 & 406 \\
Adjusted $R^{2}$ & 0.043 & 0.050 & 0.136 & 0.277 & 0.340 & 0.406 & 0.498 \\
Volume & $7,755,853$ & 392,848 & $5,761,200$ & $1,591,146$ & 475,303 & 118,293 & 6,073 \\
& & & & & & & \\
Variance Swap & Approach: & & & 0.284 & 0.143 & 0.118 & 0.021 \\
Probability & 0.615 & & & $(0.022)$ & $(0.011)$ & $(0.017)$ & $(0.035)$ \\
Standard Error & $(0.026)$ & & & 105 & 37 & 14 & 3 \\
\# Firms & 372 & & & 1,024 & 356 & 118 & 24 \\
\# Options & 3,973 & & & 20,895 & 7,363 & 2,786 & 597 \\
\# Firm-Days & 74,028 & & 40,365 & 11,903 & 3,873 & 856 \\
\# Option-Days & 152,095 & & & & & & \\
\hline
\end{tabular}

The case with standard restrictions weights by the average of the inverse relative bid-ask spread, removes firms with high dividends or low stock prices during the event window, and removes options with bids equal to zero. Extreme strikes only uses one option per firm, either the highest call option or the lowest put option with a positive bid on both election day and the day after that does not have two options with zero bids closer to the money. Positive events restricts attention to only those firms with positive stock price movement after the event. For the Out-of-the-Money Approach, each column shows the estimated probability, $\bar{p}$, if the stock return event study t-statistic is greater than the cutoff. Standard errors are clustered at both the firm and date level. The Variance Swap Approach is similar, except using $\tilde{p}$, using the absolute value of the stock return t-statistic, and clustering by date.

event of interest or some other news. ${ }^{41}$ Imposing the t-statistic cutoff would then bias our estimated probability down by leading us to estimate the probability of some unusual event that was not our target. This concern is in general legitimate, but its effect is likely minimal in this particular application. First, we examine tstatistics well beyond those that should arise with any frequency in the course of the distribution of daily news that firms experience. The 2016 U.S. election was

\footnotetext{
${ }^{41}$ Appendix A shows that the 2016 election day is a major outlier for these firms' option prices: on typical days, their option prices do not increase in a way that would indicate a probability near 0.12. Instead, as one should expect, option prices appear to be martingales in that the ratio of consecutive days' option prices is typically evenly distributed around 1. On the overwhelming majority of days, this ratio is between 0.75 and 1.25 for nearly all firms.
} 
such an enormous event for such a large number of firms that we can even examine firms with t-statistics greater than 75 . Daily news should generate such t-statistics in fewer than 1 in 100,000 firms, whereas Table 1 reports 43 such firms from the 1,835 with positive events. Second, in Appendix A we perform a robustness check in which we select for those firms whose stock price movements were strongly correlated with the PredictIt prediction market contract for a Trump victory in the run-up to the election. We show that restricting attention to those firms does not change our results.

The lower panel of Table 1 reports the $\tilde{p}$ obtained from synthesized variance swaps, as described in Section 4.2. The first column directly imposes all restrictions except for the t-statistic restrictions. We recover a probability of 0.62 , consistent with the analogous columns for $\bar{p}$. The next two columns are empty because they are not relevant to $\tilde{p}$. The remaining columns of Table 1 demonstrate how tightening the t-statistic cutoff affects the estimated $\tilde{p}$, where here the cutoff is on the absolute value of the t-statistic rather than its level. As before, imposing some restriction is critical because it eliminates firms that are not affected by the event and thus do not provide an estimate of $p_{\tau-1}^{H}$ : the estimated $\tilde{p}$ falls to 0.28 . Tightening the t-statistic cutoff to only 50 recovers a probability consistent with the converged $\bar{p} .{ }^{42}$ Tightening the t-statistic cutoff all the way to 100 does yield a much smaller probability, but at this point there are only three firms left and the standard error grows larger.

The identifying assumption underlying the variance swap approach is that the election outcome did not affect the expected variance over the remaining life of the option contracts. The election of Donald Trump would almost surely violate this assumption if we used long-dated options, but we analyze options that expire only ten days after the election. Trump would not take office for more than two further months, and he would announce his first Cabinet official only on the day these options expired. Table A-3 of Appendix A.2 provides evidence in support of the identifying assumption. It shows how our estimates of $\tilde{p}$ change when we limit our sample to only those firms with realized volatility over the 9 days after the election that is close to the realized volatility over the 9 days before the election. ${ }^{43}$ We find that results

\footnotetext{
${ }^{42}$ The number of firms is generally lower when estimating $\tilde{p}$ because we lose firms with either $\tilde{V}<0$ or fewer than three usable strikes, but the number of options is nonetheless generally greater when estimating $\tilde{p}$ because this method uses all liquid strikes rather than only a firm's most extreme liquid strike.

${ }^{43}$ The realized volatility over the 9 days after the election approximates the expected post-election variance conditional on Trump winning while the realized volatility over the 9 days leading up to the election approximates the unconditional expected post-election variance. These two variances are similar if the post-election variance is not sensitive to whether Trump wins or not. Approximating expectations of later volatility by recent realized volatility follows Martin (2017) and Zhou (2018),
} 
are not sensitive to using only those firms with the smallest differences between these approximations of conditional and unconditional expected volatility.

Figure 2 shows how the estimated $\bar{p}$ (solid line) and $\tilde{p}$ (dashed line) converge as the minimum required event study t-statistic increases. The estimated $\bar{p}$ converges for cutoffs above 70 , and the estimated $\tilde{p}$ converges for cutoffs above 30 . We should not be surprised that $\tilde{p}$ converges faster: the cutoff there serves merely to identify firms exposed to the event, whereas for $\bar{p}$ the cutoff also identifies firms for which observed out-of-the-money call options would have been nearly worthless under alternate election outcomes. The $95 \%$ confidence intervals grow in the cutoff. This increasing imprecision reflects the bias-variance tradeoff described above, as higher t-statistic cutoffs simultaneously reduce both the upward bias and the number of observed firms. Most importantly, at a t-statistic cutoff around 80, both estimators have converged to a probability around 0.12 with fairly tight standard errors - despite their different identifying assumptions and despite their reliance on different sets of options per firm. The coherence across the estimates increases our confidence in each of the individual estimates.

In sum, our new, model-free methods of estimating the risk-neutral probability of an event generate estimates that are compatible with each other and that move in expected ways as we apply restrictions meant to reduce their bias. Further, these estimates are broadly consistent with the range of estimates available from prediction markets, bookmakers, and polling-driven models. A number of recent papers have relied on event studies of this election (e.g., Mukanjari and Sterner, 2018; Wagner et al., 2018a,b; Ramelli et al., 2019). While this election was indeed more surprising than most, our results nonetheless suggest that the event study estimates should be inflated by $14 \%$ (multiplied by $1 /(1-0.12)$ ) to recover the full effect of the election.

\section{$5.2 \quad$ OPEC Meetings}

Measuring the extent to which the market anticipated an event is critical for being able to compare the relative magnitude of a series of events. We further demonstrate the power of our new approaches by analyzing a series of events involving Organization of the Petroleum Exporting Countries (OPEC) decisions on oil production quotas.

OPEC is a cartel that aims to achieve higher prices by restricting oil supply.

among others. The calculated pre-event volatility uses a regression of stock prices on the price of the PredictIt contract for Trump's victory to remove volatility associated with changes in beliefs about the event's outcome. Finally, note that these approximations are to expectations under the physical measure whereas the assumption is for expectations under the risk-neutral measure. 


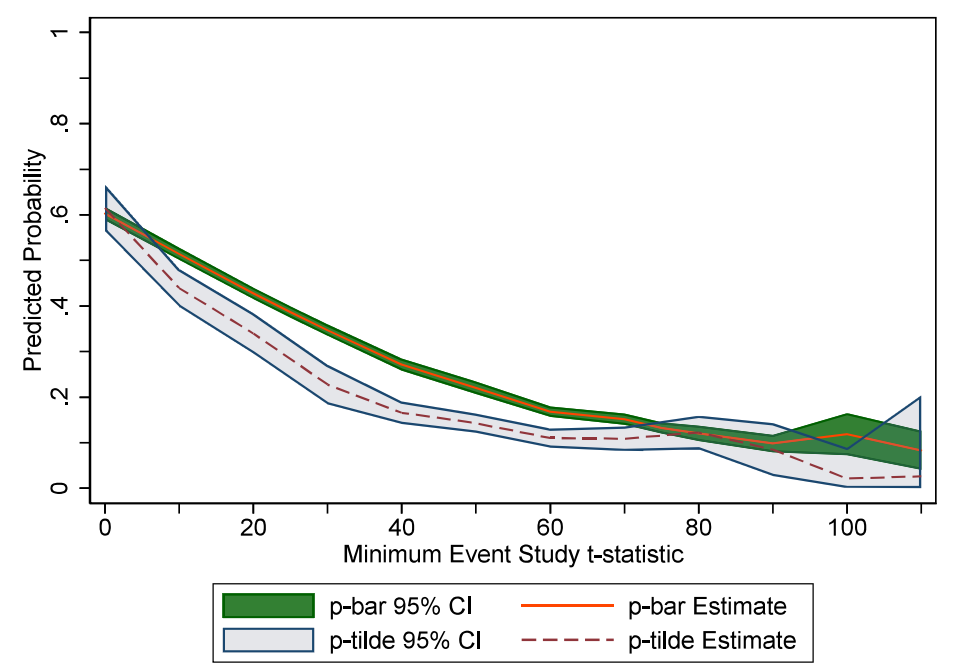

Figure 2: Estimated Probability of the 2016 Election Outcome, By Event Study t-statistic Cutoff

OPEC meets at least twice a year to assess its production quotas, with special meetings as warranted. Its meetings are typically of high interest, as the price of oil has implications throughout the global economy. There have been many event studies of OPEC meetings, but anticipation of meetings has been recognized as a problem for understanding OPEC's effect on markets dating back to the earliest work (Draper, 1984; Deaves and Krinsky, 1992). ${ }^{44}$ Differential anticipation of announcements has been proposed as an explanation for why oil markets appear to react to announcements of higher or unchanged quotas but not to smaller quotas (Hyndman, 2008; Demirer and Kutan, 2010; Loutia et al., 2016). Anticipation could also explain why oil markets' reactions appear smaller than seems reasonable (Wirl and Kujundzic, 2004) and why effects are larger when OPEC maintains the current quota because its members cannot agree as opposed to when it maintains the quota because its members agree to do so (Spencer and Bredin, 2019).

We study the announcements from 13 OPEC meetings in 2011-2016. ${ }^{45}$ Most

\footnotetext{
${ }^{44}$ Researchers have addressed anticipation by including earlier days in the event window (e.g., Draper, 1984; Loutia et al., 2016; Lauenstein and Simic, 2017) and by using realized movements to classify events as good or bad news relative to expectations (e.g., Deaves and Krinsky, 1992).

${ }^{45}$ Diego Kaenzig kindly provided the times OPEC decisions were formally announced and the times they appeared on Bloomberg news. Horan et al. (2004) show that options' implied volatil-
} 
meetings result in no change in production quotas, and press reports suggest that most of these outcomes are largely expected. ${ }^{46}$ OPEC raised its production target in November 2011 amid global economic troubles. This agreement was seen as largely symbolic, since producers had already been ignoring the old quota. However, some meetings do generate news about quotas. Most observers expected OPEC to cut production in November 2014 (see Plante, 2019) in response to sliding oil prices. Some members indeed proposed such cuts, but, at the behest of Saudi Arabia, OPEC agreed to maintain the quota. By December 2015 and June 2016, disagreement was severe enough to keep OPEC from agreeing on quotas. In September 2016 the members managed to reach a preliminary agreement to cut oil production, which was eventually finalized in a November meeting. Contemporary media reports suggest that these latter two meetings were far from foregone conclusions.

In contrast to our analysis of the 2016 election, we do not attempt to identify which firms are affected by the events. Instead, we use options on the commodity (oil) that is the subject of the meetings. In particular, we study options on front-month Brent oil futures. These futures are often used as the spot price of internationally traded oil. ${ }^{47}$

The left panel of Figure 3 displays the time-series of Brent front-month oil future prices with OPEC meeting dates. The right panel displays the event-study estimates of the abnormal return on oil futures due to each OPEC meeting, with $95 \%$ confidence intervals. ${ }^{48}$ These traditional event study estimates suggest that the OPEC meetings

ity anticipated the release of valuable information at the meetings of the Ministerial Monitoring Committee but not at the biannual conference. However, that committee no longer had power over production quotas by the time of our sample (Lin and Tamvakis, 2010), so we follow others in focusing on the biannual conference.

${ }^{46}$ OPEC meetings generate news about continuous measures of quotas and news about non-quota factors. Even though quotas are in principle continuous, they in practice seem to have only a few focal points, often round numbers. Our framework of discrete event outcomes may therefore be an adequate approximation. Regarding non-quota news, our probabilities can be viewed as recovering the joint probability of all news released, much as we recover the joint probability of Congressional and Presidential election outcomes in Section 5.1. Känzig (2019) argues that non-quota news is not very important, and Brunetti et al. (2013) provide evidence in support of this view. See Gürkaynak et al. (2020) for more on identifying non-headline news.

${ }^{47}$ There are two primary oil future prices: Brent and West Texas Intermediate (WTI). Brent futures measure the price of oil to be delivered to the North Sea and are now the primary international benchmark. WTI futures measure the price of a barrel of oil delivered to Cushing, Oklahoma and are the U.S. benchmark. These prices typically track each other but did diverge in the period of interest due to a surplus of non-tradable U.S. oil production. We focus on Brent prices because they are more directly linked to OPEC decisions. We report results with WTI prices in Appendix B.

${ }^{48}$ Event study estimates use a 120-day estimation window, including 90 days before the event and 29 days after. Controls include the future's days to expiration, its square, and an indicator for 


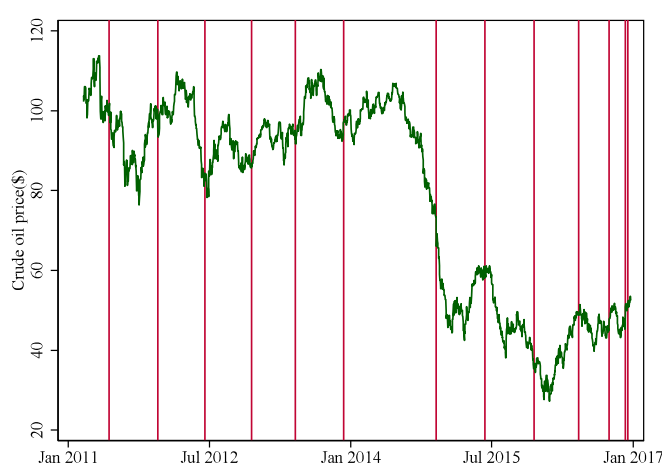

(a) Oil prices over time

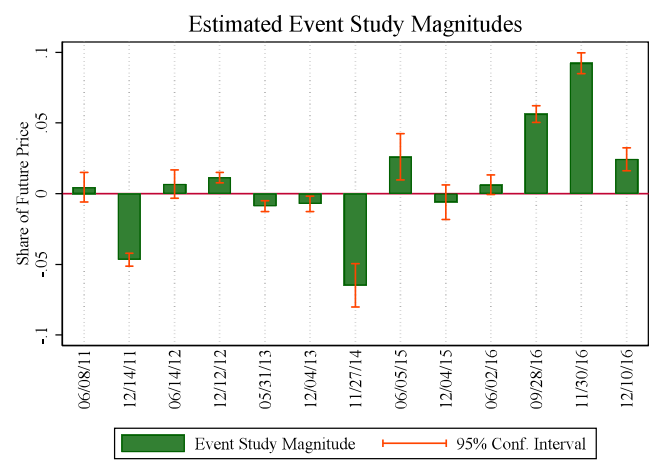

(b) Event study estimates

Figure 3: Left: Time series of Brent front-month oil future prices, with vertical lines marking OPEC meetings. Right: Traditionally-estimated event-study change in Brent front-month oil future prices (plus 95\% confidence intervals) at the date the outcome of the OPEC meeting is known.

in December 2011, November 2014, and September and November 2016 moved oil future prices substantially. Most other meetings did not have a significant effect on oil prices. Notably, the meetings in December 2015 and June 2016 - at which OPEC failed to agree on production targets - generated only minimal changes in oil prices. These small responses could suggest that the recent dramatic surge in U.S. shale oil production had limited OPEC's influence on oil markets. However, we should hesitate to draw such conclusions unless we also know the extent to which the market anticipated these meeting outcomes.

Figure 4 demonstrates the empirical approach, using the OPEC meeting on September 28, 2016 as an example. ${ }^{49}$ This meeting increased the price of oil, so we study call options. The circles depict the $\bar{p}$ implied by strike-by-strike regressions analogous to equation (13), with sizes proportional to standard errors. The line and shading indicate the estimated spline and its $95 \%$ confidence interval. The vertical line indicates the price of the oil future on the day of the event, so out-ofthe-money options have strikes to the right of the line. As expected, call options

any other OPEC meeting that falls in the estimation window. Observations are weighted by the future's average open interest over day $t$ and day $t-1$.

${ }^{49}$ We show the spline plot for the September 28, 2016 meeting because it has the lowest estimated probability of any of the OPEC meeting in our sample, which makes the variation in the estimated probability across strikes easiest to see. Appendix B contains analogous plots for every OPEC meeting in our sample. 


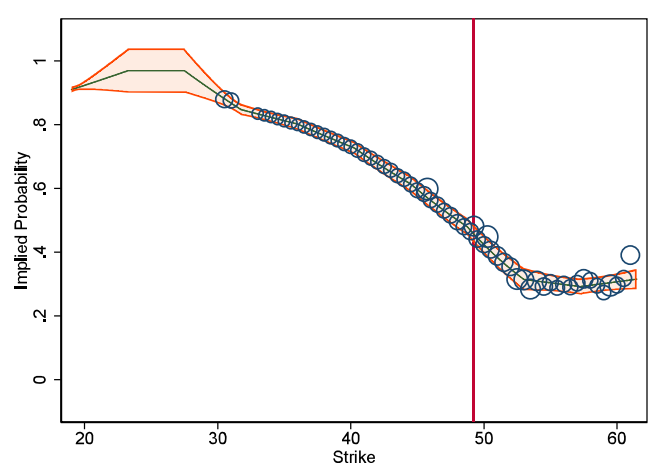

Figure 4: Estimates of $\bar{p}$ using Brent front-month call options for the September 28, 2016 OPEC meeting. Circles represent estimates using only that strike and weighting by the average inverse of the bid-ask ratio. Circle sizes are proportional to the standard error of the estimate. The green line is the spline with 10 knots, and orange shading is the $95 \%$ confidence interval. The minimum of the spline is our preferred estimate of the meeting outcome's probability.

at lower strikes do appear to produce upward-biased estimates of the event probability. On the other hand, deeper out-of-the-money (higher-strike) estimates of the event's probability exhibit both larger standard errors and more noise across strikes, reflecting a bias-variance trade-off similar to that seen across firms in Figure 2. The spline combines the information across strikes. Its minimum occurs at a probability of 0.29 , with a standard error of 0.0129 .

Figure B-4 in Appendix B compares the estimated $\bar{p}$ and $\tilde{p}$. The two approaches yield quite similar estimates despite their distinct identifying assumptions: the unweighted correlation between the two estimates is 0.68 , and the correlation is 0.88 when weighting by the inverse of an event's average standard error across the two approaches. As with the 2016 election, the coherence between the two sets of estimates increases confidence in each. Unfortunately, we recover $\tilde{p}$ only for 6 of the 13 meetings, with the other meetings' estimated probabilities being uninformative (i.e., $\tilde{V}$ is negative; see Proposition 1). We proceed by using $\bar{p}$ in order to take advantage of the full sample of meetings.

The left panel of Figure 5 depicts the $\bar{p}$ graphically. Green dots indicate how estimated probabilities relate to the effect estimated from a traditional event study (as in Figure 3). Events that we find to have high probability (such as meetings in December 2015 and June 2016) generally have small event study estimates, while 


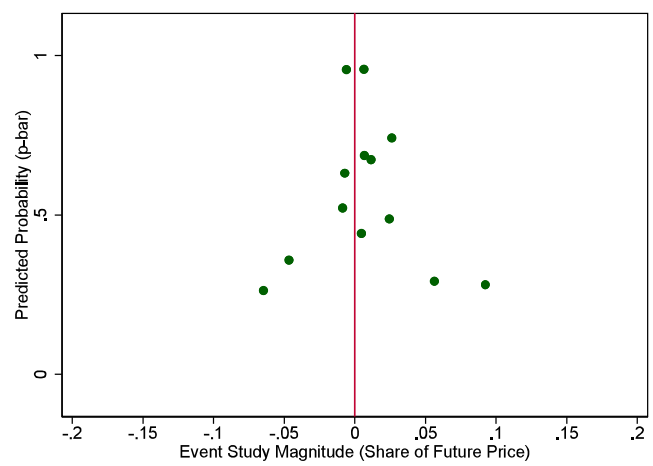

(a) $\bar{p}$ against estimated event study effects

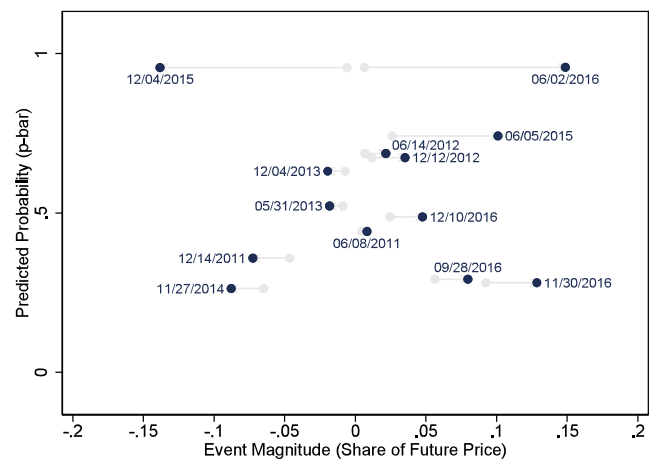

(b) $\bar{p}$ against adjusted event study effects

Figure 5: Panel (a): Green circles plot predicted event probabilities $\bar{p}$ against conventional event study estimates. Panel (b): Blue circles plot predicted event probabilities $\bar{p}$ against event study estimates adjusted for the event probabilities (conventional event study estimates are in light gray for comparison).

meetings with large event study estimates (such as November 2014 and November 2016) tend to be more surprising. The blue dots in the right panel of Figure 5 show how adjusting for these estimated probabilities changes our understanding of which meetings were important (conventional event study estimates are in light gray for comparison). After adjusting for the estimated probability of the meeting outcome, there is little correlation between the event-study effect of the meeting on oil future prices and the market's predicted probability of the meeting outcome.

Figure 6 displays the original (orange) and adjusted event study estimates (green), organized according to the timeline of meetings and with $95 \%$ confidence intervals. The traditional event study estimates systematically underestimate OPEC's effect on oil markets, sometimes substantially. Meetings in December 2015 and June 2016 may have had the largest impact on oil prices, although these two adjusted estimate are imprecise. ${ }^{50}$ Standard event studies did not detect this impact because the meetings' outcomes were well-anticipated. These meetings are particularly interesting because OPEC failed to agree on new production quotas. That failure was important, even though expected. ${ }^{51}$

\footnotetext{
${ }^{50}$ Confidence intervals become wide when conventionally estimated event effects are small and imprecise because adjusting for the event probability makes larger positive values and larger negative values both more likely.

${ }^{51}$ See Spencer and Bredin (2019) for more on the importance of failing to agree on new quotas versus agreeing to maintain quotas.
} 


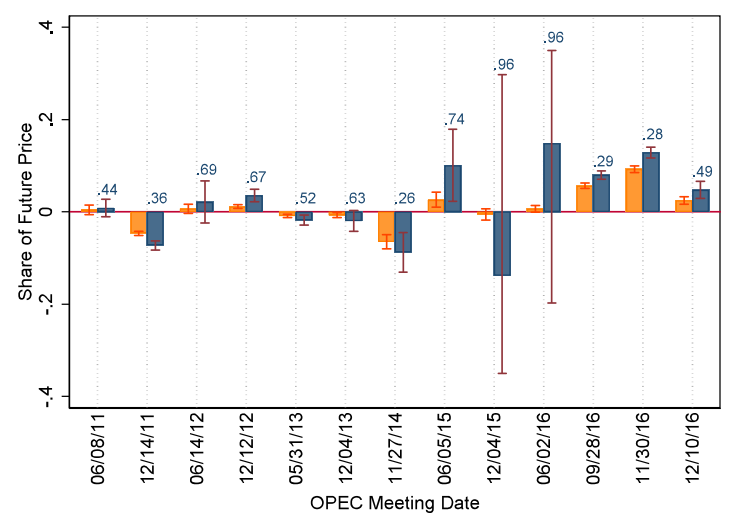

Figure 6: Orange bars plot conventional event study estimates, and blue bars adjust for event probabilities. 95\% confidence intervals are truncated at event study magnitudes of -0.35 and $0.35 . \bar{p}$ is printed above each blue bar.

Overall, these results highlight the importance of estimating event probabilities. We find that OPEC meetings did not strongly affect oil prices in 2012 and 2013 but did substantially impact oil prices from late 2014 through 2016. In standard event study estimates, the market's anticipation of meeting outcomes in 2015 and June 2016 obscures the meetings' true importance for oil prices. As a result, standard event studies detect impacts from OPEC decisions only once OPEC actually begins reaching agreements to cut production. However, our probability-adjusted estimates show that OPEC substantially affected world oil markets even during a period in which it was not changing production and during which U.S. shale oil producers had become a substantial force in world markets.

\section{Conclusions}

We have demonstrated how to use time series variation in option prices to estimate the priced-in probability of events. In contrast to prior literature, our two new approaches do not impose parametric models on the evolution of stock prices. Both approaches boil down to running event studies in option prices to complement conventional event studies in stock prices. We show that our approaches appear to work in practice. Each approach estimates a probability for President Trump's 2016 election victory that is consistent with the range of probabilities implied by bookmakers, prediction markets, and polling-driven models. Importantly, the estimated probabilities are consistent with each other, despite relying on distinct identifying 
assumptions. We also estimate probabilities for OPEC meetings that are consistent across the two estimators, that vary in ways consistent with narrative evidence, and that improve our understanding of the importance of OPEC for oil markets.

Our new methods come with two caveats. First, we recover the probability of a realized event, but some event studies seek the probability of a future policy whose odds are merely shifted by the event, as when an election increases the chance of tax reform. Our estimated probabilities are useful in these cases, but they are only part of the adjustment required to recover the full effect of the policy from the event study estimate. Second, we recover the probability of an event as of the day before the event occurred. In some cases, researchers seek a time series of pre-event probabilities in order to analyze the evolution of uncertainty about an event (e.g., Carvalho and Guimaraes, 2018). One could in principle construct such a time series using our methods, but doing so would challenge the identifying assumptions underpinning the event study regressions used to estimate the probabilities.

Future researchers should use our new methods to improve event study estimates for cost-benefit analyses. For instance, many researchers have used event studies to assess the Affordable Care Act and minimum wage laws. Adjusting for estimated event probabilities could substantially revise such assessments. Future researchers should also use our new methods to improve analyses of economic policy uncertainty. Such work often relies on textual evidence and only recently has begun to measure firm-level exposure to uncertainty. Our techniques offer a new revealed preference measure of firm-level uncertainty. This measure could be used to understand and validate existing aggregated measures of policy uncertainty and could provide a crosssectional dimension when testing for effects of uncertainty on economic activity.

\section{References}

Acharya, Sankarshan (1993) "Value of latent information: Alternative event study methods," The Journal of Finance, Vol. 48, No. 1, pp. 363-385.

Al-Ississ, Mohamad M and Nolan H Miller (2013) "What does health reform mean for the health care industry? Evidence from the Massachusetts special Senate election," American Economic Journal: Economic Policy, Vol. 5, No. 3, pp. 1-29.

Auerbach, Alan J. and Kevin A. Hassett (2007) "The 2003 dividend tax cuts and the value of the firm: An event study," in Alan J. Auerbach, James R. Hines Jr., and Joel Slemrod eds. Taxing Corporate Income in the 21st Century, Cambridge: Cambridge University Press, pp. 93-126. 
Baker, Scott R., Nicholas Bloom, Brandice Canes-Wrone, Steven J. Davis, and Jonathan A. Rodden (2014) "Why has U.S. policy uncertainty risen since 1960?" Working Paper 19826, National Bureau of Economic Research.

Ball, Ray (1972) "Changes in accounting techniques and stock prices," Journal of Accounting Research, Vol. 10, pp. 1-38.

Barraclough, Kathryn, David T. Robinson, Tom Smith, and Robert E. Whaley (2013) "Using option prices to infer overpayments and synergies in M\&A transactions," Review of Financial Studies, Vol. 26, No. 3, pp. 695-722.

Barro, Robert J. (2006) "Rare disasters and asset markets in the twentieth century," The Quarterly Journal of Economics, Vol. 121, No. 3, pp. 823-866.

Barro, Robert J. and José F. Ursúa (2012) "Rare macroeconomic disasters," Annual Review of Economics, Vol. 4, No. 1, pp. 83-109.

Bates, David S. (2000) "Post-' 87 crash fears in the S\&P 500 futures option market," Journal of Econometrics, Vol. 94, No. 1, pp. 181-238.

Beber, Alessandro and Michael W. Brandt (2006) "The effect of macroeconomic news on beliefs and preferences: Evidence from the options market," Journal of Monetary Economics, Vol. 53, No. 8, pp. 1997-2039.

Bell, Brian and Stephen Machin (2017) "Minimum wages and firm value," Journal of Labor Economics, Vol. 36, No. 1, pp. 159-195.

Bhagat, Sanjai and Roberta Romano (2002) "Event studies and the law: Part II: Empirical studies of corporate law," American Law and Economics Review, Vol. 4, No. 2, pp. 380-423.

Bianconi, Marcelo, Federico Esposito, and Marco Sammon (2020) "Trade policy uncertainty and stock returns," working Paper.

Binder, John J. (1985) "Measuring the effects of regulation with stock price data," The RAND Journal of Economics, Vol. 16, No. 2, pp. 167-183.

Björk, Tomas (2004) Arbitrage Theory in Continuous Time, Oxford; New York: Oxford University Press, 2nd edition.

Black, Fischer (1975) "Fact and fantasy in the use of options," Financial Analysts Journal, Vol. 31, No. 4, pp. 36-41, Publisher: Routledge _eprint: https://doi.org/10.2469/faj.v31.n4.36. 
Borochin, Paul and Joseph Golec (2016) "Using options to measure the full valueeffect of an event: Application to Obamacare," Journal of Financial Economics, Vol. 120, No. 1, pp. 169-193.

Bronars, Stephen G. and Donald R. Deere (1990) "Union representation elelctions and firm profitability," Industrial Relations: A Journal of Economy and Society, Vol. 29, No. 1, pp. 15-37.

Brown, Stephen J. and Jerold B. Warner (1985) "Using daily stock returns: The case of event studies," Journal of Financial Economics, Vol. 14, No. 1, pp. 3-31.

Brunetti, Celso, Bahattin Büyükşahin, Michel A. Robe, and Kirsten R. Soneson (2013) "OPEC "fair price" pronouncements and the market price of crude oil," The Energy Journal, Vol. 34, No. 4, pp. 79-108.

Bushnell, James B., Howard Chong, and Erin T. Mansur (2013) "Profiting from regulation: Evidence from the European carbon market," American Economic Journal: Economic Policy, Vol. 5, No. 4, pp. 78-106.

Campbell, John Y., Andrew W. Lo, and Craig MacKinlay (1997) The Econometrics of Financial Markets, Princeton N.J.: Princeton University Press.

Card, David and Alan B. Krueger (1995) Myth and Measurement, Princeton, NJ: Princeton University Press.

Carr, Peter and Roger Lee (2009) "Volatility derivatives," Annual Review of Financial Economics, Vol. 1, No. 1, pp. 319-339.

Carr, Peter and Liuren Wu (2009) "Variance risk premiums," Review of Financial Studies, Vol. 22, No. 3, pp. 1311-1341.

Carvalho, Augusto and Bernardo Guimaraes (2018) "State-controlled companies and political risk: Evidence from the 2014 Brazilian election," Journal of Public Economics, Vol. 159, pp. 66-78.

Caughey, Devin and Jasjeet S. Sekhon (2011) "Elections and the regression discontinuity design: Lessons from close U.S. house races, 1942-2008," Political Analysis, Vol. 19, No. 4, pp. 385-408.

Cboe (2019) "VIX White Paper,"Technical report, Cboe Exchange, Inc., http:// www. cboe.com/products/vix-index-volatility/vix-options-and-futures/ vix-index/the-vix-index-calculation. 
Chaudhury, Mohammed M. and Jason Wei (1994) "Upper bounds for American futures options: A note," Journal of Futures Markets, Vol. 14, No. 1, pp. 111-116.

Cochrane, John H. (2005) Asset Pricing, Princeton, N.J: Princeton University Press, revised edition.

Cornell, Bradford and R. Gregory Morgan (1990) "Using finance theory to measure damages in fraud on the market cases," UCLA Law Review, Vol. 37, pp. 883-924.

Deaves, Richard and Itzhak Krinsky (1992) "The behavior of oil futures returns around OPEC conferences," Journal of Futures Markets, Vol. 12, No. 5, pp. 563574 .

Demirer, Riza and Ali M. Kutan (2010) "The behavior of crude oil spot and futures prices around OPEC and SPR announcements: An event study perspective," Energy Economics, Vol. 32, No. 6, pp. 1467-1476.

Dorsey, Jackson (2019) "Waiting for the courts: Effects of policy uncertainty on pollution and investment," Environmental and Resource Economics, Vol. 74, No. 4, pp. 1453-1496.

Draper, Dennis W. (1984) "The behavior of event-related returns on oil futures contracts," Journal of Futures Markets, Vol. 4, No. 2, pp. 125-132.

Dube, Arindrajit, Ethan Kaplan, and Suresh Naidu (2011) "Coups, corporations, and classified information," The Quarterly Journal of Economics, Vol. 126, No. 3, pp. 1375-1409.

Dubinsky, Andrew, Michael Johannes, Andreas Kaeck, and Norman J. Seeger (2019) "Option pricing of earnings announcement risks," The Review of Financial Studies, Vol. 32, No. 2, pp. 646-687.

Easley, David, Maureen O'Hara, and P. S. Srinivas (1998) "Option volume and stock prices: Evidence on where informed traders trade," The Journal of Finance, Vol. 53, No. 2, pp. 431-465, Publisher: [American Finance Association, Wiley].

Farber, Henry S. and Kevin F. Hallock (2009) "The changing relationship between job loss announcements and stock prices: 1970-1999," Labour Economics, Vol. 16, No. 1, pp. 1-11.

Fisman, Raymond and Eric Zitzewitz (2019) "An event long-short index: Theory and application," American Economic Review: Insights, Vol. 1, No. 3, pp. 357-372. 
Gemmill, Gordon (1992) "Political risk and market efficiency: Tests based in British stock and options markets in the 1987 election," Journal of Banking \& Finance, Vol. 16, No. 1, pp. 211-231.

Grinblatt, Mark and Kam-Ming Wan (2020) "State pricing, effectively complete markets, and corporate finance," Journal of Corporate Finance, Vol. 60, p. 101542.

Gürkaynak, Refet S., Burçin Kısacıkoğlu, and Jonathan H. Wright (2020) "Missing events in event studies: Identifying the effects of partially-measured news surprises," American Economic Review, Vol. 110, No. 12, pp. 3871-3912.

Hallock, Kevin F. (1998) "Layoffs, top executive pay, and firm performance," The American Economic Review, Vol. 88, No. 4, pp. 711-723.

Handley, Kyle and J. Frank Li (2020) "Measuring the effects of firm uncertainty on economic activity: New evidence from one million documents," Working Paper 27896, National Bureau of Economic Research.

Hassan, Tarek A., Stephan Hollander, Laurence van Lent, and Ahmed Tahoun (2019) "Firm-level political risk: Measurement and effects," Quarterly Journal of Economics, Vol. 134, No. 4, pp. 2135-2202.

Hennessy, Christopher A. and Ilya A. Strebulaev (2020) "Beyond random assignment: Credible inference of causal effects in dynamic economies," Journal of Finance, Vol. 75, No. 2, pp. 825-866.

Herron, Michael C. (2000) "Estimating the economic impact of political party competition in the 1992 British election," American Journal of Political Science, Vol. 44, No. 2, pp. 326-337.

Horan, S.M., J.H. Peterson, and J. Mahar (2004) "Implied volatility of oil futures options surrounding OPEC meetings," Energy Journal, Vol. 25, No. 3, pp. 103125.

Hughes, Paul (2006) "Do EPA defendants prefer Republicans? Evidence from the 2000 election," Economic Inquiry, Vol. 44, No. 3, pp. 579-585.

Hyndman, Kyle (2008) "Disagreement in bargaining: An empirical analysis of OPEC," International Journal of Industrial Organization, Vol. 26, No. 3, pp. 811828. 
Imai, Masami and Cameron A. Shelton (2011) "Elections and political risk: New evidence from the 2008 Taiwanese Presidential Election," Journal of Public Economics, Vol. 95, No. 7, pp. 837-849.

Jackwerth, Jens Carsten and Mark Rubinstein (1996) "Recovering probability distributions from option prices," The Journal of Finance, Vol. 51, No. 5, pp. 1611-1631.

Jayachandran, Seema (2006) "The Jeffords effect," The Journal of Law and Economics, Vol. 49, No. 2, pp. 397-425.

Jiang, George J. and Yisong S. Tian (2005) "The model-free implied volatility and its information content," The Review of Financial Studies, Vol. 18, No. 4, pp. $1305-1342$.

Johnson, Travis L. and Eric C. So (2012) "The option to stock volume ratio and future returns," Journal of Financial Economics, Vol. 106, No. 2, pp. 262-286.

Känzig, Diego R. (2019) "The macroeconomic effects of oil supply news: Evidence from OPEC announcements," working paper.

Karpoff, Jonathan M., Paul H. Malatesta, and Ralph A. Walkling (1996) "Corporate governance and shareholder initiatives: Empirical evidence," Journal of Financial Economics, Vol. 42, No. 3, pp. 365-395.

Kelly, Bryan, Lubos Pastor, and Pietro Veronesi (2016) "The price of political uncertainty: Theory and evidence from the option market," Journal of Finance, Vol. 71, No. 5, pp. 2417-2480.

Knight, Brian (2006) "Are policy platforms capitalized into equity prices? Evidence from the Bush/Gore 2000 Presidential Election," Journal of Public Economics, Vol. 90 , No. 4-5, pp. $751-773$.

Kogan, Leonid, Dimitris Papanikolaou, Amit Seru, and Noah Stoffman (2017) "Technological innovation, resource allocation, and growth," Quarterly Journal of Economics, Vol. 132, No. 2, pp. 665-712.

Kothari, S. P. and Jerold B. Warner (1997) "Measuring long-horizon security price performance," Journal of Financial Economics, Vol. 43, No. 3, pp. 301-339.

Kothari, S.P. and Jerold B. Warner (2007) "Econometrics of event studies," in B. Espen Eckbo ed. Handbook of Empirical Corporate Finance, San Diego: Elsevier, pp. 3-36, doi:10.1016/B978-0-444-53265-7.50015-9. 
Lamdin, Douglas J. (2001) "Implementing and interpreting event studies of regulatory changes," Journal of Economics and Business, Vol. 53, No. 2-3, pp. 171-183.

Lanen, William N. and Rex Thompson (1988) "Stock price reactions as surrogates for the net cash flow effects of corporate policy decisions," Journal of Accounting and Economics, Vol. 10, No. 4, pp. 311-334.

Lange, Ian and Joshua Linn (2008) "Bush v. Gore and the effect of New Source Review on power plant emissions," Environmental and Resource Economics, Vol. 40, No. 4, pp. 571-591.

Lauenstein, Philipp and André Küster Simic (2017) "Information processing in freight and freight forward markets: an event study on OPEC announcements," International Journal of Financial Markets and Derivatives, Vol. 6, No. 2, p. 149.

Lee, David S. (2008) "Randomized experiments from non-random selection in U.S. House elections," Journal of Econometrics, Vol. 142, No. 2, pp. 675-697.

Lee, David S. and Alexandre Mas (2012) "Long-run impacts of unions on firms: New evidence from financial markets, 1961-1999," The Quarterly Journal of Economics, Vol. 127, No. 1, pp. 333-378.

Lemoine, Derek (2017) "Green expectations: Current effects of anticipated carbon pricing," Review of Economics and Statistics, Vol. 99, No. 3, pp. 499-513.

Lin, Sharon Xiaowen and Michael Tamvakis (2010) "OPEC announcements and their effects on crude oil prices," Energy Policy, Vol. 38, No. 2, pp. 1010-1016.

Linn, Joshua (2010) "The effect of cap-and-trade programs on firms' profits: Evidence from the Nitrogen Oxides Budget Trading Program," Journal of Environmental Economics and Management, Vol. 59, No. 1, pp. 1-14.

Loutia, Amine, Constantin Mellios, and Kostas Andriosopoulos (2016) "Do OPEC announcements influence oil prices?" Energy Policy, Vol. 90, pp. 262-272.

MacKinlay, A. Craig (1997) "Event studies in economics and finance," Journal of Economic Literature, Vol. 35, No. 1, pp. 13-39.

Madhavan, Ananth (2000) "Market microstructure: A survey," Journal of Financial Markets, Vol. 3, No. 3, pp. 205-258. 
Malatesta, Paul H. and Rex Thompson (1985) "Partially anticipated events: A model of stock price reactions with an application to corporate acquisitions," Journal of Financial Economics, Vol. 14, No. 2, pp. 237-250.

Martin, Ian (2017) "What is the expected return on the market?" The Quarterly Journal of Economics, Vol. 132, No. 1, pp. 367-433.

Melick, William R. and Charles P. Thomas (1997) "Recovering an asset's implied PDF from option prices: An application to crude oil during the Gulf crisis," Journal of Financial and Quantitative Analysis, Vol. 32, No. 1, pp. 91-115.

Meng, Kyle C. (2017) "Using a free permit rule to forecast the marginal abatement cost of proposed climate policy," American Economic Review, Vol. 107, No. 3, pp. $748-784$.

Mukanjari, Samson and Thomas Sterner (2018) "Do markets trump politics? Evidence from fossil market reactions to the Paris Agreement and the U.S. election," Working Papers in Economics 728, University of Gothenburg, Department of Economics.

Pan, Jun and Allen M. Poteshman (2006) "The information in option volume for future stock prices," The Review of Financial Studies, Vol. 19, No. 3, pp. 871-908, Publisher: Oxford Academic.

Patell, James M. and Mark A. Wolfson (1979) "Anticipated information releases reflected in call option prices," Journal of Accounting and Economics, Vol. 1, No. 2, pp. $117-140$.

(1981) "The ex ante and ex post price effects of quarterly earnings announcements reflected in option and stock prices," Journal of Accounting Research, Vol. 19, No. 2, pp. 434-458.

Plante, Michael (2019) "OPEC in the news," Energy Economics, Vol. 80, pp. 163172.

Ramelli, Stefano, Alexander F. Wagner, Richard J. Zeckhauser, and Alexandre Ziegler (2019) "Stock price rewards to climate saints and sinners: Evidence from the Trump election," Working Paper 25310, National Bureau of Economic Research.

Rietz, Thomas A. (1988) "The equity risk premium: A solution," Journal of Monetary Economics, Vol. 22, No. 1, pp. 117-131. 
Roberts, Brian E. (1990) "Political institutions, policy expectations, and the 1980 election: A financial market perspective," American Journal of Political Science, Vol. 34, No. 2, pp. 289-310.

Rubinstein, Mark (1994) "Implied binomial trees," The Journal of Finance, Vol. 49, No. 3, pp. $771-818$.

Snowberg, Erik, Justin Wolfers, and Eric Zitzewitz (2007) "Partisan impacts on the economy: Evidence from prediction markets and close elections," The Quarterly Journal of Economics, Vol. 122, No. 2, pp. 807-829.

(2011) "How prediction markets can save event studies," in L. V. Williams ed. Prediction Markets: Theory and Applications, New York: Routledge, pp. 1834 .

Spencer, Simon and Don Bredin (2019) "Agreement matters: OPEC announcement effects on WTI term structure," Energy Economics, Vol. 80, pp. 589-609.

van Tassel, Peter (2016) "Merger options and risk arbitrage,"Technical Report 761, Federal Reserve Bank of New York.

Vayanos, Dimitri and Jiang Wang (2013) "Market liquidity — Theory and empirical evidence," in George M. Constantinides, Milton Harris, and Rene M. Stulz eds. Handbook of the Economics of Finance, Vol. 2: Elsevier, pp. 1289-1361.

Wagner, Alexander F., Richard J. Zeckhauser, and Alexandre Ziegler (2018a) "Unequal rewards to firms: Stock market responses to the Trump election and the 2017 corporate tax reform," AEA Papers and Proceedings, Vol. 108, pp. 590-596.

_ (2018b) "Company stock price reactions to the 2016 election shock: Trump, taxes, and trade," Journal of Financial Economics, Vol. 130, No. 2, pp. 428-451.

Wirl, Franz and Azra Kujundzic (2004) "The impact of OPEC conference outcomes on world oil prices 1984-2001," The Energy Journal, Vol. 25, No. 1, pp. 45-62.

Wolfers, Justin and Eric Zitzewitz (2009) "Using markets to inform policy: The case of the Iraq war," Economica, Vol. 76, No. 302, pp. 225-250.

Zhou, Hao (2018) "Variance risk premia, asset predictability puzzles, and macroeconomic uncertainty," Annual Review of Financial Economics, Vol. 10, No. 1, pp. 481-497. 